\title{
镍催化的烯丙基取代反应研究进展
}

\author{
张慧君 ${ }^{a}$ 顾 庆*,b游书力 $*, a, b$ \\ ( ${ }^{a}$ 华东理工大学化学与分子工程学院 上海 200237) \\ ( ${ }^{b}$ 中国科学院上海有机化学研究所 金属有机化学国家重点实验室 上海 200032)
}

\begin{abstract}
摘要 过渡金属催化的烯丙基取代反应是构建碳一碳键、碳一杂原子键的重要手段. 由于镍价廉易得, 适用性广, 赢得了 化学家们的广泛青睐. 在过去 50 年里, 关于镍催化的烯丙基取代反应的报道不断涌现. 根据成键类型及亲核试剂的种 类进行划分，总结近年来镍催化的烯丙基取代反应的进展及其在有机合成中的应用.

关键词＼cjkstart烯丙基取代; 不对称催化; 镍; 过渡金属
\end{abstract}

\section{Recent Advances in Ni-Catalyzed Allylic Substitution Reactions}

\author{
Zhang, Huijun ${ }^{a} \quad$ Gu, Qing ${ }^{*, b} \quad$ You, Shuli ${ }^{*, a, b}$ \\ ( ${ }^{a}$ School of Chemistry and Molecular Engineering, East China University of Science and Technology, Shanghai 200237) \\ ( ${ }^{b}$ State Key Laboratory of Organometallic Chemistry, Shanghai Institute of Organic Chemistry, \\ Chinese Academy of Sciences, Shanghai 200032)
}

\begin{abstract}
Transition-metal catalyzed allylic substitution reaction is an important approach for constructing carbon-carbon bond and carbon-heteroatom bond. Due to its cheapness, easy access, and wide applicability in organic synthesis, nickel has attracted intense attention. Over the past 50 years, nickel-catalyzed allylic substitution reactions have been extensively studied. The progresses on nickel-catalyzed allylic substitution reactions and their applications in organic synthesis are summarized according to bond formation and nucleophilic reagent.
\end{abstract}

Keywords allylic substitution; asymmetric catalysis; nickel; transition metal

过渡金属催化的烯丙基取代反应是构建碳一碳键、 碳一杂原子键的有效方法, 在有机合成中占有重要地位.

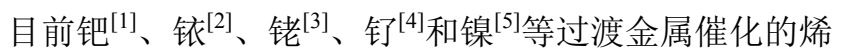
丙基取代反应已被化学家们研究报道, 其中关于钯和铱 催化的烯丙基取代反应研究最为广泛. 烯丙基取代的反 应历程首先是金属与烯丙基底物的双键配位, 然后与底 物中的离去基团发生氧化加成, 生成金属 $\pi$-烯丙基中间 体，接受亲核试剂进攻，最后金属与烯烃解离生成产物， 释放催化剂完成催化循环. 根据亲核试剂软硬度的不 同, 分别经历不同的过程. 软亲核试剂 $\left(\mathrm{p} K_{\mathrm{a}}<25\right.$, 如稳 定的碳负离子或烯醇化物、杂原子等亲核试剂)通常直 接进攻 $\pi$-烯丙基中间体发生取代反应。硬亲核试剂 $\left(\mathrm{p} K_{\mathrm{a}}>25\right.$, 如格氏试剂、有机嗍、有机锌和有机锡等金
属试剂)首先进攻 $\pi$-烯丙基中间体的金属中心，然后发 生还原消除生成烯丙基取代产物(Scheme 1).

在钯催化的不对称烯丙基取代反应中, 软亲核试剂 参与的反应研究广泛且取得了优秀的对映选择性, 而硬 亲核试剂参与的反应，其不对称控制相对困难. 镍与钯 在元素周期表中位于同一族, 具有相似的催化活性, 然 而, 在镍催化的反应中, 硬亲核试剂参与的烯丙基取代 反应研究居多. 通常除格氏试剂外, 反应性较低的有机 金属化合物如嗍试剂和锌试剂也可以作为亲核试剂参 与反应，这些试剂具有更好的官能团兼容性，其稳定性 也较高. 另一方面, 镍的储量丰富且价格低廉. 以摩尔 计, 镍成本为钯的 $0.05 \%$ 和铂金的 $0.01 \%{ }^{[6]}$. 更重要的 是，镍自身具有许多特征，使其不仅仅作为钯的替代物，

\footnotetext{
* Corresponding authors. E-mail: qinggu@sioc.ac.cn; slyou@sioc.ac.cn

Received September 28, 2018; revised October 22, 2018; published online October 26, 2018.

Dedicated to Professor Qingyun Chen on the occasion of his 90th birthday.

Project supported by the National Key R\&D Program of China (No. 2016YFA0202900), the National Basic Research Program of China (973 Program, No. 2015CB856600), the National Natural Science Foundation of China (Nos. 21332009, 21572250, 21572252), and the Chinese Academy Sciences (Nos. XDB20000000, QYZDY-SSW-SLH012).

国家重点研发计划(No. 2016YFA0202900)、国家重点基础研究发展计划(973 计划, No. 2015CB856600)、国家自然科学基金(Nos. 21332009, 21572250, 21572252)、中国科学院(Nos. XDB20000000, QYZDY-SSW-SLH012)资助项目.
} 
例如, 更小的原子半径, 更强的亲核性, 与亲电试剂更 容易发生氧化加成等 ${ }^{[7]}$. 在过去 50 年里, 关于镍催化的 烯丙基取代反应的报道不断涌现. 本文主要根据成键类 型及亲核试剂的种类进行划分, 总结近年来镍催化的烯 丙基取代反应的进展及其在有机合成中的应用.

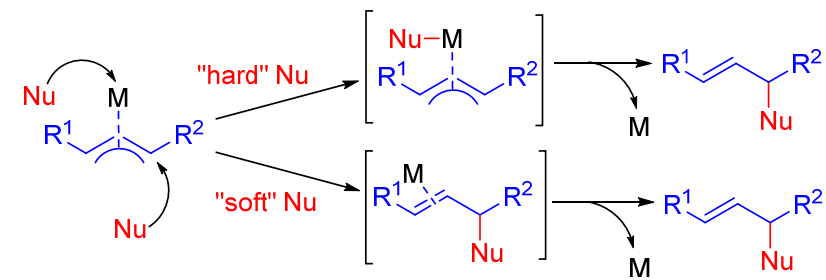

图式 1 软亲核试剂与硬亲核试剂的两种反应路径 Scheme 1 Two reaction paths for "soft" nucleophile and "hard" nucleophile

\section{1 碳一碳键的构建}

\section{1 格氏试剂作为亲核试剂}

在镍催化烯丙基取代反应中, 格氏试剂是最早使用 的亲核试剂. 早在 20 世纪 60 年代, Felkin 等 ${ }^{[8]}$ 就报道了 $\mathrm{Ni}\left(\mathrm{PPh}_{3}\right)_{2} \mathrm{Cl}_{2}$ 催化的烯丙醇和格氏试剂的取代反应, 该 反应在乙醚回流下进行，通常得到混合产物. 例如， $\alpha$ 甲基烯丙醇与甲基溴化镁反应, 以 $82 \%$ 的总收率得到比 例为 $71: 29$ 的支链和直链的混合物(Eq. 1). 在随后的研 究中, 他们认为异构体的产生是因为反应过程中经历了 $\pi$-烯丙基镍中间体 ${ }^{[9]}$, 并提出了可能的反应机理 ${ }^{[10]}$. $\mathrm{Ni}\left(\mathrm{PPh}_{3}\right)_{2} \mathrm{Cl}_{2}$ 经甲基澳化镁还原后产生零价 $\mathrm{Ni}$, 随后与 烯烃配位生成中间体 1,1 又与甲基溴化镁反应，经历 $\pi-$ 烯丙基镍中间体 2, 随后还原消除生成区域异构体 3, 最 后配位解离分别生成支链和直链产物, 并释放催化剂完 成催化循环(Scheme 2).

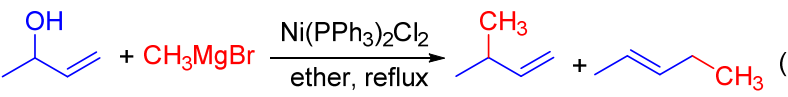

$$
\begin{aligned}
& 82 \% \text { yield } \\
& B: L=71: 29
\end{aligned}
$$

1980 年, Consiglio 等 ${ }^{[11]}$ 发现使用 $[(-)-(R)-1,2$-双(二 苯基膦基)-1-苯基乙烷]镍氯化物可以催化烯丙醇与格 氏试剂的不对称烷基化反应, 但只获得很低的对映选择 性. 他们认为如果使用具有 $C_{2}$ 对称性的手性双膦配体, 可以减少过渡态中间体非对映体的数目, 进而提高反应 的对映选择性. 随后, Consiglio 小组 ${ }^{[12]}$ 使用 $C_{2}$ 对称性的 手性配体 ( $S, S)$-双 (二苯基膦)丁烷(chiraphos), 实现了支 链、直链以及环状烯丙基化合物与格氏试剂的不对称取 代反应, 为合成具有光学活性的烯烃提供了两种可行的 方法: 一是使用非手性烯丙基底物与外消旋格氏试剂反 应获得手性产物, 如烯丙基苯基醚和 1-苯基乙基氯化镁

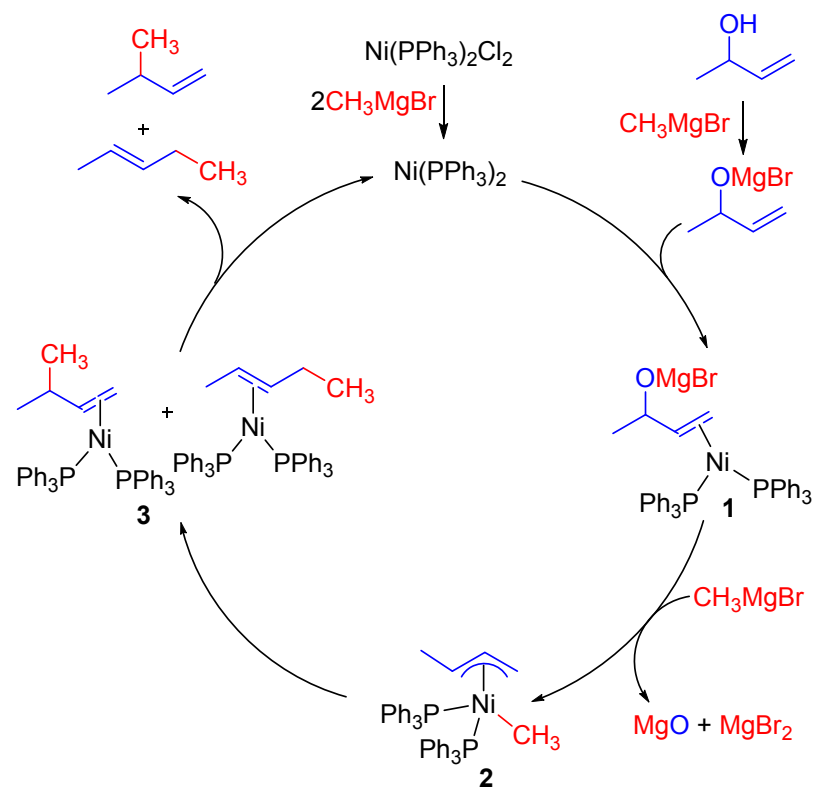

图式 2 烯丙醇与格氏试剂可能的反应机理

Scheme 2 Proposed mechanism of the reaction of allylic alcohols with Grignard reagents

反应，获得了 $58.3 \%$ ee 的取代产物 ${ }^{[13]}$ (Eq. 2); 二是使用 外消旋烯丙基化合物与非手性格氏试剂反应获得手性 产物, 如 1-苯氧基-2-环戊烯和乙基澳化镁反应, 获得了 $90.4 \%$ ee 的取代产物 ${ }^{[13]}$ (Eq. 3). 与此相似的, Hiyama 小 组 ${ }^{[14]}$ 也使用 $(S, S)$-chiraphos 作手性配体，烯丙基叔丁酯 与芳基格氏试剂在 $0{ }^{\circ} \mathrm{C}$ 下反应，以 50\%收率和 $89 \% \mathrm{ee}$ 生成 $R$ 构型的支链产物, 同时还有收率为 $25 \%$ 的直链副 产物(Eq. 4).
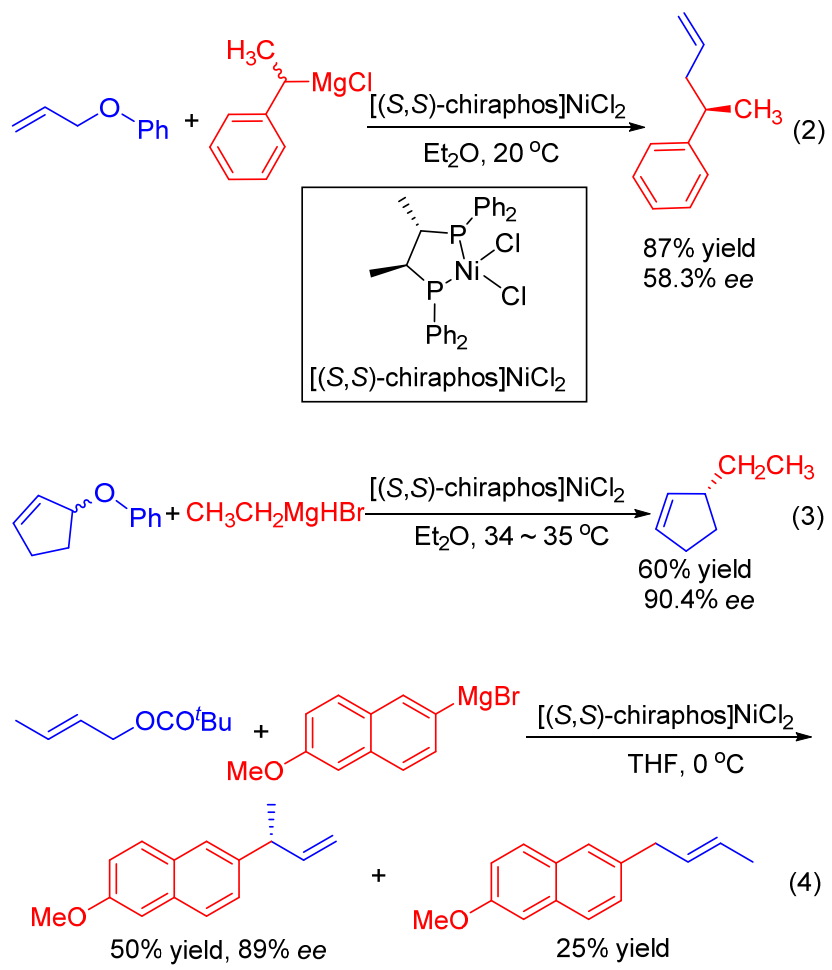
镍催化不对称烯丙基取代反应的效率和对映选择 性高度依赖于所使用的亲核试剂和配体, 实现优秀的对 映选择性依旧困难, 但上述初步的研究成果引起了化学 家们的关注. 1997 年, RajanBabu 小组 ${ }^{[15]}$ 报道了格氏试剂 与 1,3-二苯基烯丙基醚的不对称取代反应. 在 $\mathrm{Ni}(\operatorname{cod})_{2} /$ $[(S, S)$-chiraphos]催化下, 外消旋的 3-甲氧基-1,3-二苯基1-丙烯与甲基溴化镁反应 $20 \mathrm{~h}$ 后, 以 $74 \% e e$ 得到甲基取 代手性产物(Eq. 5). 值得注意的是, 反应中存在一定的 动力学拆分效应, 以 $26 \%$ 收率和 $79 \%$ ee 回收了原料.

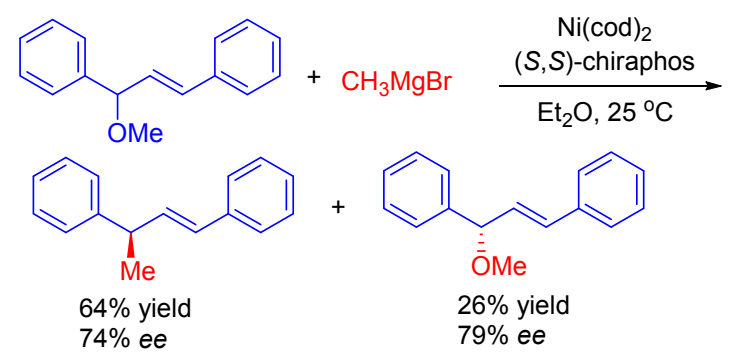

为了实现高对映选择性的镍催化不对称烯丙基取 代反应, Hoveyda 小组 ${ }^{[16]}$ 报道了不饱和环状缩酮与格氏 试剂反应. 反应后如经碱处理可以生成手性烯醇醚产 物, 如经过酸处理则生成手性酤产物. 该反应芳基和烷 基格氏试剂都能顺利地发生. 特别需要指出的是, 加入 额外的 $\mathrm{PPh}_{3}$ 配体对反应的对映选择性有很大影响. 对 于 2-环己烯-1-酮缩二甲醇与正丁基氯化镁的反应, 以 $\mathrm{Ni}\left(\mathrm{PPh}_{3}\right)_{2} \mathrm{Cl}_{2} /[(S, S)$-chiraphos $]$ 作为催化剂, 需要加入 5 $20 \mathrm{~mol}_{\mathrm{o}} \mathrm{PPh}_{3}$. 不加入 $\mathrm{PPh}_{3}$ 时仅得到消旋产物, 而加入 $10 \mathrm{~mol}^{2} \mathrm{PPh}_{3}$, 反应可以获得最优 $85 \% \mathrm{ee}$ 的对映选择性 (表 1, Entry 3).

表 $1 \mathrm{PPh}_{3}$ 对于反应对映选择性的影响

Table 1 Influence of $\mathrm{PPh}_{3}$ on enantioselectivity

\begin{tabular}{|c|c|c|c|}
\hline \multirow{2}{*}{\multicolumn{2}{|c|}{$X^{\mathrm{MeO}}+{ }^{n} \mathrm{BuMgCl}$}} & $\begin{array}{c}\text { (1) } \mathrm{Ni}\left(\mathrm{PPh}_{3}\right)_{2} \mathrm{Cl}_{2}(5 \mathrm{~mol} \%) \\
\text { (S, S)-chiraphos }(5 \mathrm{~mol} \%) \\
\mathrm{PPh}_{3}(x \mathrm{~mol} \%) \\
22^{\circ} \mathrm{C}\end{array}$ & \\
\hline & & (2) $10 \% \mathrm{HCl}$ (aq.) & \\
\hline Entry & $x / \mathrm{mol} \%$ & Yield/\% & $e e / \%$ \\
\hline 1 & None & 50 & 0 \\
\hline 2 & 5 & 65 & 82 \\
\hline 3 & 10 & 85 & 85 \\
\hline 4 & 20 & 81 & 76 \\
\hline
\end{tabular}

2000 年, Uemura 小组 ${ }^{[17]}$ 将平面手性 P,N 配体应用到 烯丙基醚与格氏试剂的取代反应中. 当使用二茂铁惡唑 啉(L1)作为手性配体时，3-环己烯醚与芳基格氏试剂反 应，以 30\% 100\%的收率和 14\% 95\% ee 得到芳基取 代的产物. 其中, 3-环已烯苯基醚与 2-䒺基溴化镁反应
可以获得最高 $95 \%$ ee 的对映选择性(Eq. 6).

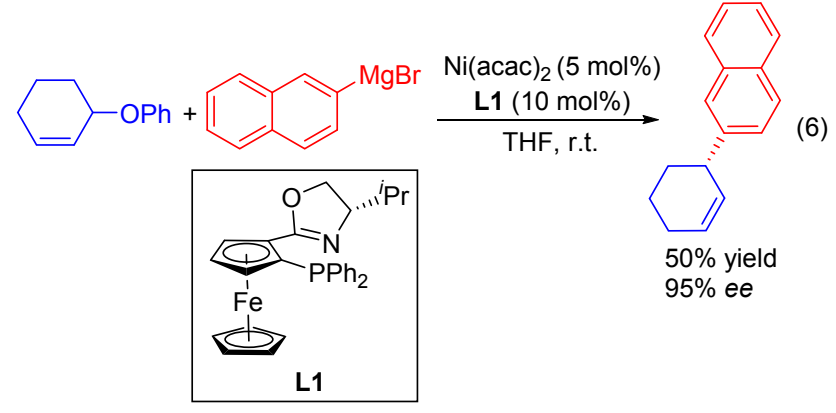

\section{2 硼试剂作为亲核试剂}

硼酸衍生物方便易得, 对水不敏感, 可以兼容多种 官能团，因此是一类备受青睐的反应试剂. 1995 年, Trost 和 Spagnol 小组 ${ }^{[18]}$ 发展了嗍酸衍生物作为亲核试 剂，烯丙基胺作为烯丙基前体的烯丙基取代反应. $\mathrm{Ni}(\operatorname{cod})_{2}$ 作为镍源, 氢氧化钾作碱, 在甲苯回流条件下, 实现了各种芳基和烯基硼试剂的烯丙基取代反应. 当使 用 1,1'-联菜-2,2'-双(二苯基亚膦酸酯)(BINAPO)作配体 时，3-吡咯烷基-1-丁烯与苯硼酸反应，以 $69 \%$ 的总收率 得到直链和支链混合物, 反应优先发生在烯丙基取代较 多的一端生成支链产物(Eq. 7).
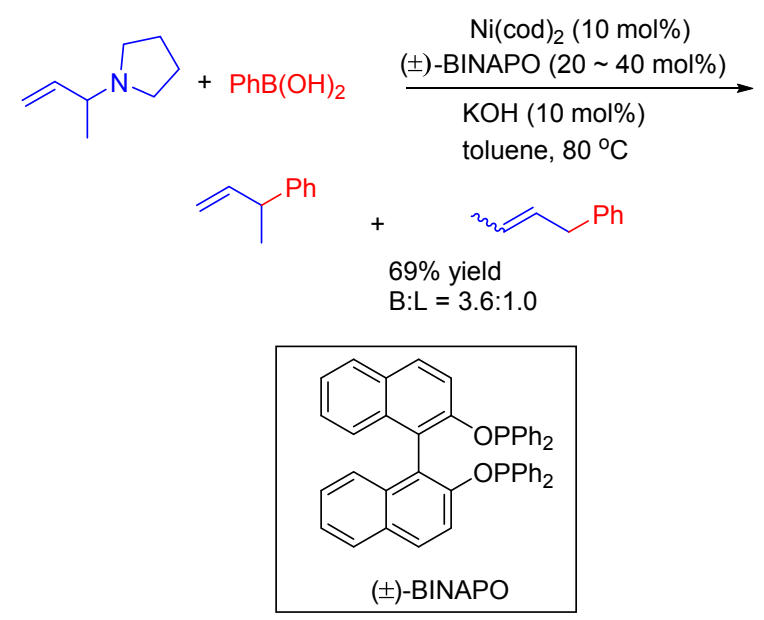

Kobayashi 小组 ${ }^{[19]}$ 也发展了一系列镍催化的有机硼 试剂与烯丙醇衍生物的反应. 例如, 碳酸酯 $\mathbf{4 a}$ 与硼酸盐 5 在 $\mathrm{Ni}(\mathrm{dppf}) \mathrm{Cl}_{2}$ 催化下生成苯基取代的产物 ${ }^{[19 \mathrm{a}]} ; \mathbf{4 a}$ 与苯 乙烯基嘲酸盐 6 在 $\mathrm{Ni}(\mathrm{dppf}) \mathrm{Cl}_{2}$ 催化下生成苯乙烯基取代 的产物 ${ }^{[19 a]}$; 醋酸酯 $4 \mathbf{b}$ 与锌嗍酸盐 7 在 $\mathrm{Ni}\left(\mathrm{PPh}_{3}\right)_{2} \mathrm{Cl}_{2}$ 催 化下生成苯基取代的产物 ${ }^{[19 b]}$ (Scheme 3). 这些反应条件 温和, 通常在室温下进行. 反应中使用的硣酸盐制备相 对简单，可以由相应的金属试剂分别和乙炔、溴乙炔、 醛等反应得到. 1996 年, 该小组 ${ }^{[19 \mathrm{c}]}$ 运用该策略成功实现 了(+)-Brefeldin A 的形式全合成. 在 $\mathrm{Ni}\left(\mathrm{PPh}_{3}\right)_{2} \mathrm{Cl}_{2}$ 的催 化下, 对映纯的环戊烯二醇单乙酸酯 8 和 2-呋喃基喼酸 
三甲酯锂盐以良好的立体选择性和区域选择性生成呋 喃取代产物 9 和 10, 比例为 $88: 12$. 以 9 为原料可以实 现(+)-Brefeldin A 的形式全合成(Scheme 4). 1998 年, 该 小组 ${ }^{[19 \mathrm{~d}, 19 \mathrm{e}]}$ 将该策略又成功运用到 Prostaglandin (PG)中 间体的不对称合成中. 单乙酸酯 $\mathbf{8}$ 与烯基硼酸盐 11 反应 以 21:1 的比例得到 1,3-异构体 12 与 1,2-异构体 $\mathbf{1 3}$ (Scheme 4). 反式 1,3-异构体 12 是合成多种前列腺素衍 生物的通用中间体. 2011 年, 该小组 ${ }^{[19 f]}$ 又报道了烯丙醇 与烯丙基硼试剂的分子间反应, 可以以优秀的直链选择 性和 $\gamma$ 选择性得到 1,5-二烯烃.

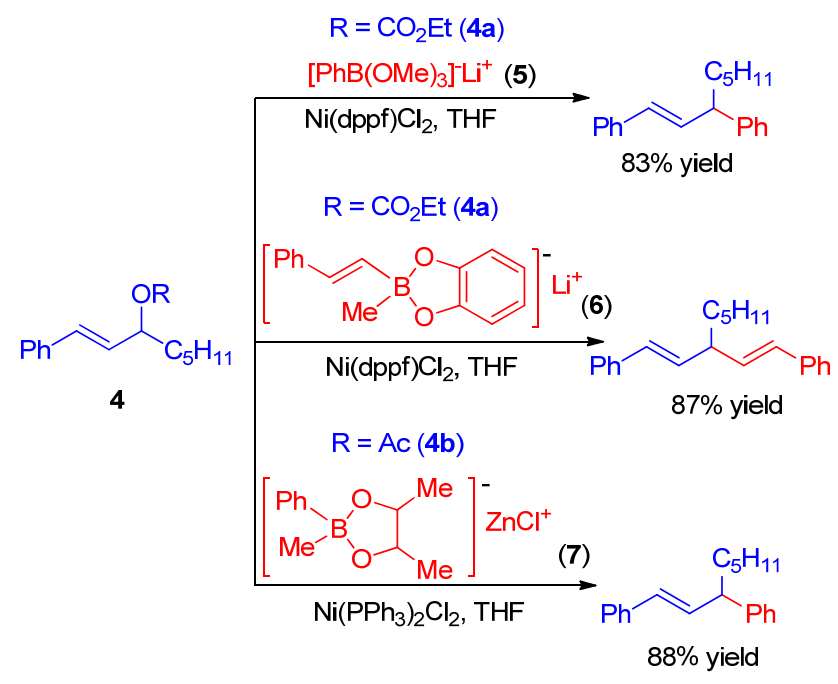

图式 3 有机嗍试剂与烯丙醇衍生物的反应

Scheme 3 Reactions of organoboron reagents with allylic alcohol derivatives

嘲试剂参与的不对称烯丙基取代反应发展较为缓 慢. 如前所述, Uemura 小组 ${ }^{[17]}$ 率先使用二茂铁噁唑啉 $\mathrm{P}, \mathrm{N}$ 配体，实现了格氏试剂参与的不对称烯丙基取代反
应. 2000 年，他们 ${ }^{[20]}$ 又将该类型配体应用到烯丙基醋酸 酯与芳基硼酸的取代反应中(Eq. 8), 以中等到良好的收 率得到苯基取代产物，对映选择性最高达 $53 \% \mathrm{ee}$. 邓敏 智小组 ${ }^{[21]}$ 使用末端炔烃与丁基锂和硼酸三甲酯反应制 备得到的炔基硼酸盐作为亲核试剂, 在 $\mathrm{Ni}(\mathrm{dppe}) \mathrm{Cl}_{2}$ 存 在下，炔基硼酸盐与肉桂基碳酸酯发生烯丙基取代反 应，以中等到良好收率(54\%～93\%)得到 1-炔-4-烯产物。 若使用 $(S, S)$-chiraphos 作为手性配体，反应能获得 $13 \%$ ee 的不对称控制(Eq. 9).

Doyle 小组 ${ }^{[22]}$ 报道了 $\mathrm{Ni}$ 催化的 $N, O$-乙缩醛和芳基 嗍酸的取代反应. 研究表明该反应经历镍-亚铵活化模 式 ${ }^{[22 \mathrm{a}]}$. 首先在芳基硼酸的作用下, $N$-乙氧酰基-2-乙氧 基-1,2-二氢喹啉(14)生成亚铵离子 15,15 与镍发生氧化 加成生成 $\pi$-烯丙基镍中间体 16, 随后接受喼试剂进攻, 最后生成取代产物 17 (Scheme 5). 在机理研究上, 他们 分离得到了 $\pi$-烯丙基镍中间体 $\mathbf{1 8}^{[22 b]}$ ，并通过单晶 $\mathrm{X}$ 射 线衍射进行了表征. 通过这种活化模式，他们获得了一 系列 2-芳基-1,2-二氢喹啉产物 ${ }^{[22 \mathrm{c}]}$ (Eq. 10). 这对研究喹 啉类化合物不对称芳基化反应提供了新思路. 2014 年, 该小组 ${ }^{[22 \mathrm{a}]}$ 使用手性单膦配体 $\mathbf{L 3}$ 和 $[\text { (methallyl) } \mathrm{NiCl}]_{2}$ 以 优秀的对映选择性实现了嗍酸与 $N$-乙氧酰基-2-乙氧 基-1,2-二氢喹啉的不对称取代反应，产物最高取得 $90 \%$ ee 对映选择性(Eq. 11).

Watson 小组 ${ }^{[23]}$ 使用 $\mathrm{BnPPh}_{2}$ 配体, $\mathrm{NaOMe}$ 作碱, 实 现了 1,3-二取代烯丙基戊酸酯与芳基环硼氧烷手性专一 的取代反应(Eq. 12). 芳基环嗍氧烷在该体系下表现出 优秀的官能团兼容性，能够容忍乙烯基、酯基、醚、氟、 氯、三氟甲基和缩醛等官能团. 吸电子取代的和给电子 取代的芳基环硼氧烷都能够顺利发生反应，以最高达

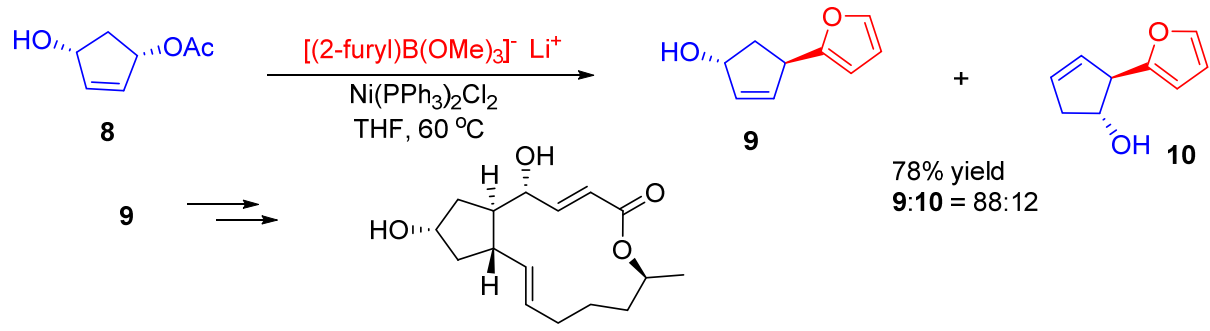

(+)-Brefeldin A

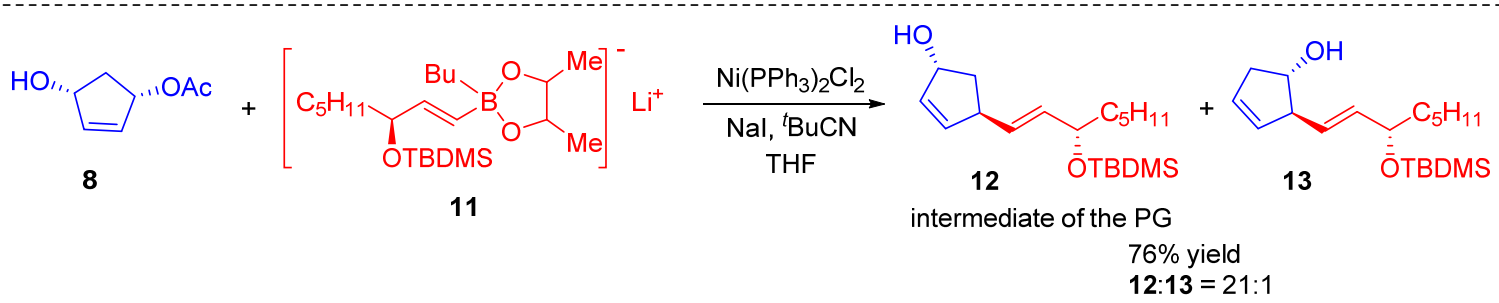

图式 4 反应在手性合成中的应用

Scheme 4 Applications in asymmetric synthesis 


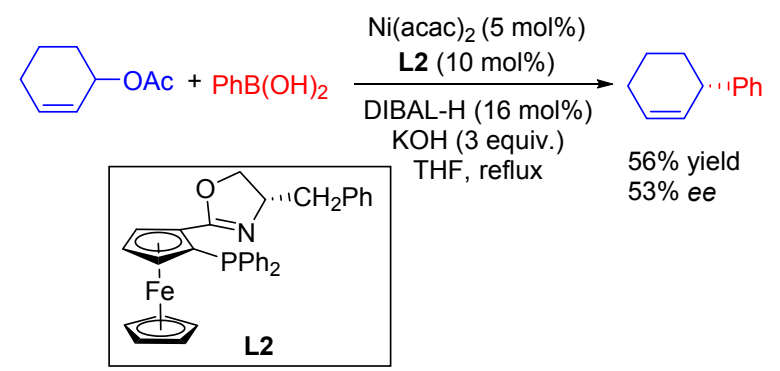

$\mathrm{OCO}_{2} \mathrm{Et}+\left[\mathrm{Ph}=\mathrm{B}(\mathrm{OMe})_{3}\right]^{-} \mathrm{Li}^{+}$ $\underset{\mathrm{THF}}{\stackrel{[(S, S) \text {-chiraphos }] \mathrm{NiCl}_{2}(5 \mathrm{~mol} \%)}{\longrightarrow}} \stackrel{\mathrm{Ph}}{\mathrm{SiMe}_{3}}$

$67 \%$ yield, $13 \%$ ee

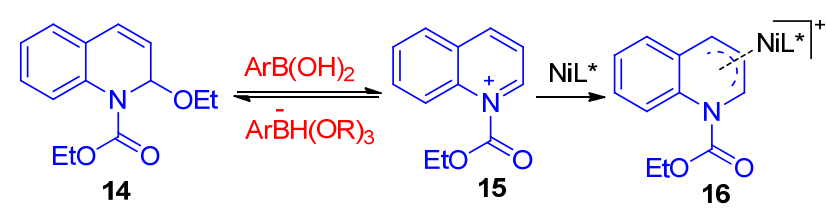
$\stackrel{\mathrm{Ar}^{\mathrm{B}} \mathrm{H}(\mathrm{OR})_{3}}{\longrightarrow}$<smiles>CN1c2ccccc2C=CC1Br</smiles><smiles>CCOC(C)=O</smiles>
17<smiles>C#Cc1ccccc1-c1ccccc1-c1ccccc1-c1ccccc1P(O)c1ccccc1</smiles>
18

图式 5 镍-亚铵活化模式

Scheme 5 Ni-iminium activation mode

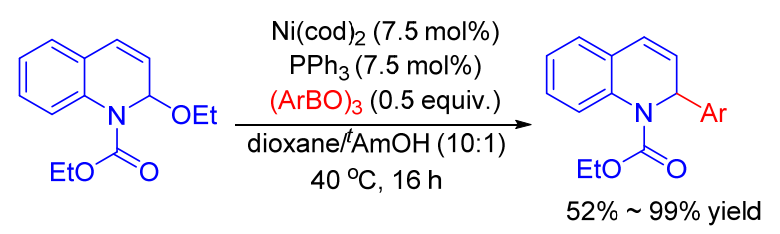

95\%的收率和 $96 \% e e$ 的对映选择性获得 1,3-二芳基烯丙 基化合物. 作者通过( $S$ )-19 的芳基取代反应获得 95\% ee 的化合物 $(R)-\mathbf{2 0},(R)-\mathbf{2 0}$ 通过后续转化合成抗炎药 $(S)$-Ketoprofen, 证明了该方法的实用性(Scheme 6).

Michaelis 小组 ${ }^{[24]}$ 使用由咪唑盐 $\mathbf{L 4}$ 现场生成的氮杂 环卡宾作为配体，应用到镍催化的烯丙基取代反应中. Ni-NHC 配合物能够高效催化芳基氧杂嗍烷与烯丙基醇 反应, 取得 57\% 98\%的收率(Eq. 13). 他们通过单晶 $\mathrm{X}$

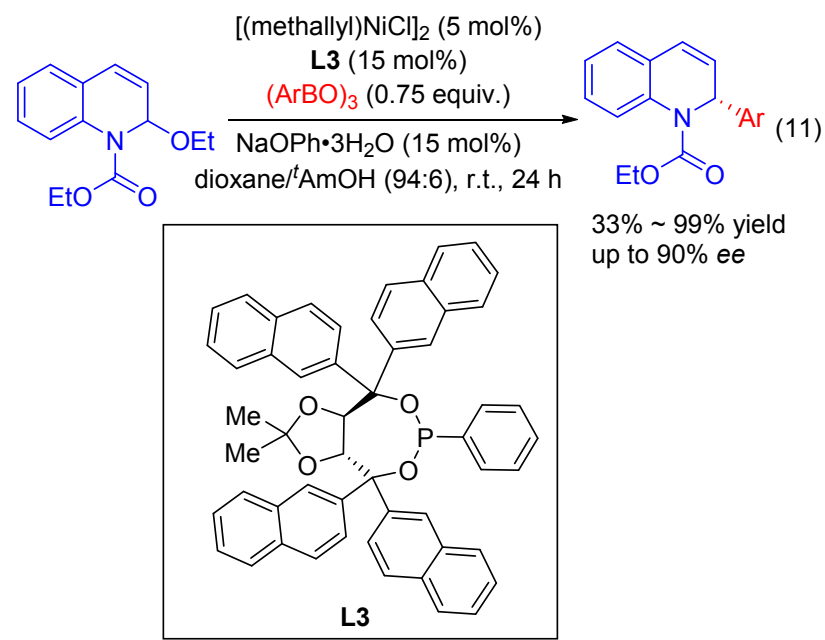

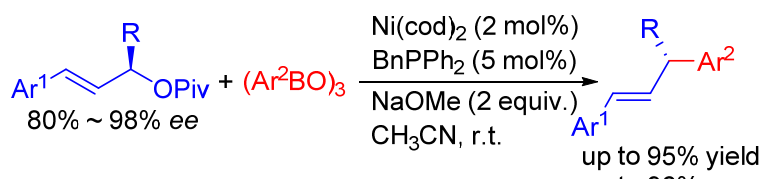

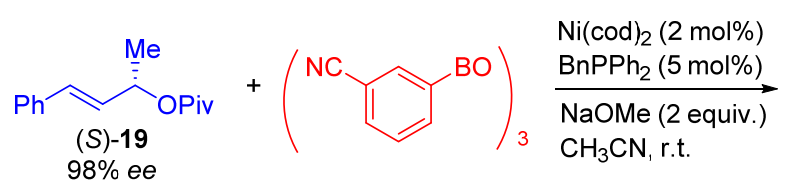

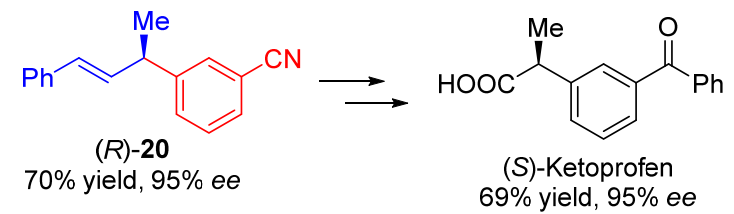

图式 $6(S)$-Ketoprofen 的合成

Scheme 6 Synthesis of $(S)$-ketoprofen

射线衍射确认了中间体配合物 21 的结构，结果表明双 齿 NHC 配体能够提高催化剂稳定性, 延长催化剂寿命, 从而提高催化反应的效率.

\section{3 锌试剂作为亲核试剂}

尽管镍催化格氏试剂、有机硼试剂等参与的烯丙基 取代反应已经取得重要进展，但亲核试剂的多样性和官 能团兼容性还有待进一步提高. 有机锌试剂, 相比有机 嗍、有机硅和有机锡试剂具有更高的反应活性，相比格 氏试剂具有更好的官能团兼容性. Doyle 小组 ${ }^{[25]}$ 发展了 4-甲氧基吡啶盐与芳基锌试剂的不对称取代反应，获得 $\alpha$-取代哌啶化合物(Eq. 14). 这类化合物是生物活性小 分子中非常普遍的片段, 也是天然产物和药物合成的重 要砌块 ${ }^{[26]}$. 作者提出了可能的反应机理(Scheme 7), 零 价镍与吡啶盐发生氧化加成, 生成二价镍烯丙基中间体 22, 22 再与芳基溴化锌发生转金属化，得到中间体 23, 经还原消除再生催化剂, 并生成产物烯基醚 24. 24 在酸 
<smiles>[R]C=CC([R])O</smiles><smiles>CC1(C)COB([Ga])OC1</smiles>
[(TMEDA)Ni(o-tolyl)Cl] $(1.25 \mathrm{~mol} \%)$ L4 (1.25 mol\%) ${ }^{t} \mathrm{BuOK}(1.25 \mathrm{~mol} \%)$ $\mathrm{K}_{3} \mathrm{PO}_{4}$ (1.5 equiv.) $\mathrm{MeCN}, 100^{\circ} \mathrm{C}$

$$
\text { or }
$$
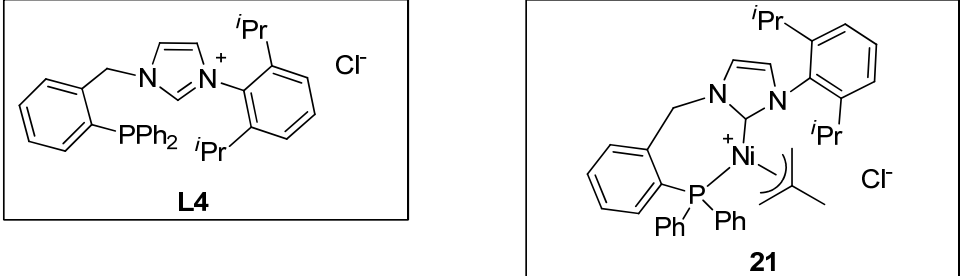

(1) $\mathrm{ArZnBr}$<smiles>COc1ccnc(CC(C)(C(=O)OCc2ccccc2)C(F)(F)F)c1</smiles>
$\mathrm{NiBr}_{2} \cdot$ diglyme $(10 \mathrm{~mol} \%)$ L5 (12 mol\%) $\mathrm{THF},-78 \sim 40^{\circ} \mathrm{C}$

(2) $1 \mathrm{~mol} / \mathrm{L} \mathrm{HCl}$ (aq.)

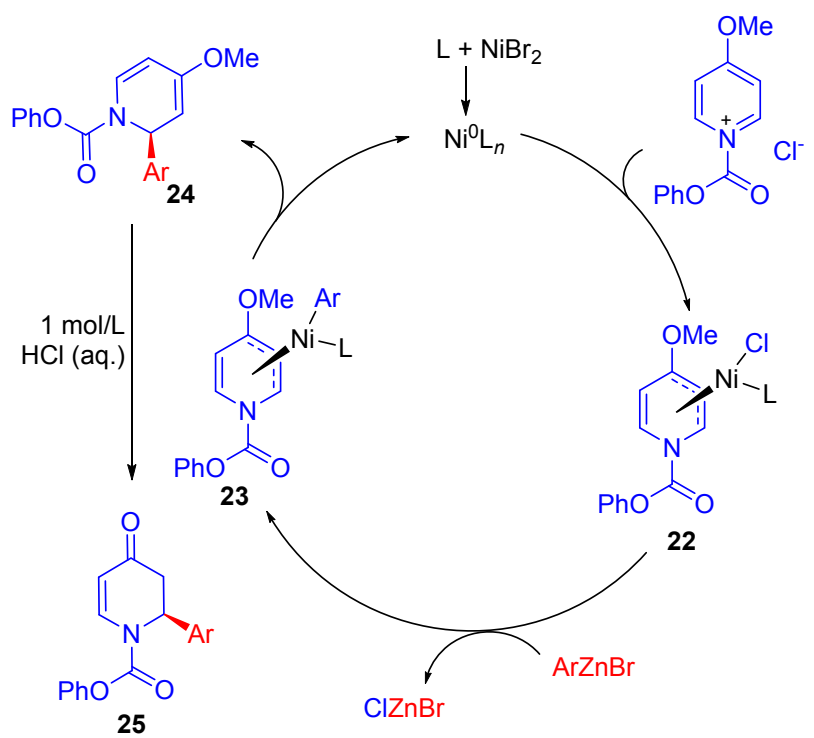

图式 7 镍催化吡啶盐的对映选择性芳基化可能的催化循环 Scheme 7 Proposed catalytic cycle of nickel-catalyzed enantioselective arylation of pyridinium ion

性条件下水解生成哌啶酮 25.

在之前工作中, 王中夏小组 ${ }^{[27]}$ 已经证明了 $\mathrm{P}, \mathrm{N}, \mathrm{N}-\mathrm{Ni}$ 配合物可有效催化芳基锌试剂的偶联反应. 2015 年, 他 们 $^{[28]}$ 发现 P,N,N-Ni 配合物还可以高效催化烯丙基甲基 醚与芳基氯化锌的取代反应，使用 $0.1 \mathrm{~mol} \% \mathrm{Cl}$, 反应 可以获得良好到优秀的收率和优秀的区域选择性(Eq. 15). 在绝大多数例子中, 反应专一地生成直链反式烯 烃产物. 反应区域选择性可能是共轭效应和位阻效应共 同作用的结果, 芳基锌试剂与 $\pi$-烯丙基镍中间体反应时
共轭效应起主要作用，增强共轭效应并且尽量减小空间 位阻, 因此优先生成直链产物. 2017 年, 王中夏小组 ${ }^{[29]}$ 进一步实现了烯丙醇与芳基或烯基氯化锌的烯丙基取 代反应。

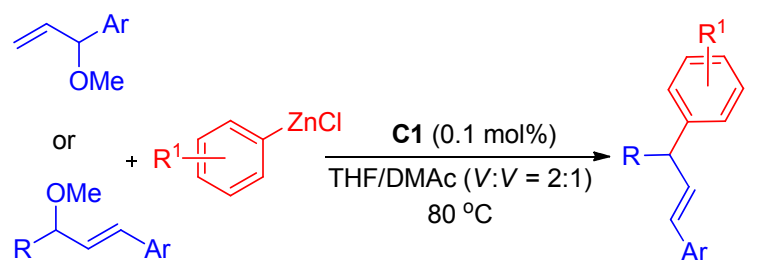

$\mathrm{R}=\mathrm{H}$, alkyl

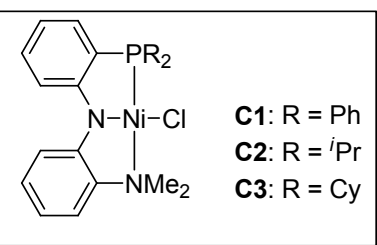

$77 \% \sim 97 \%$ yield

\section{4 软亲核试剂}

1995 年, Mortreux 小组 ${ }^{[30]}$ 发现丙二酸二甲酯能够作 为亲核试剂参与镍催化烯丙基取代反应. 随后，该课题 组 ${ }^{[31]}$ 发展了丙二酸二甲酯与烯丙基醋酸酯的取代反应. $\mathrm{Ni}(\operatorname{cod})_{2} / 1,4$-双 (二苯基膦)丁烷(dppb)或 $\mathrm{Ni}(\operatorname{cod})_{2} / N, N^{\prime}$-双 (二苯基膦)- $N, N^{\prime}$-二甲基乙二胺(dppmae)能催化反应的 进行, 获得直链和支链混合产物(Eq. 16). 以环己烯醋酸 酯与丙二酸二甲酯为模板反应，作者对一系列手性配体 进行了考察. 当使用 $(S)$-1-二苯基膦-5-二苯基膦氧甲 基-2-吡咯烷酮 $[(S)$-Ph,Ph-oxoProNOP]作配体时，THF 作 溶剂, $50{ }^{\circ} \mathrm{C}$ 下反应 $14 \mathrm{~h}$, 取得几乎定量的收率，并且实 
现了 $40 \% e e$ 的对映选择性(Eq. 17). 这是首例软亲核试 剂参与的镍催化不对称烯丙基烷基化反应.
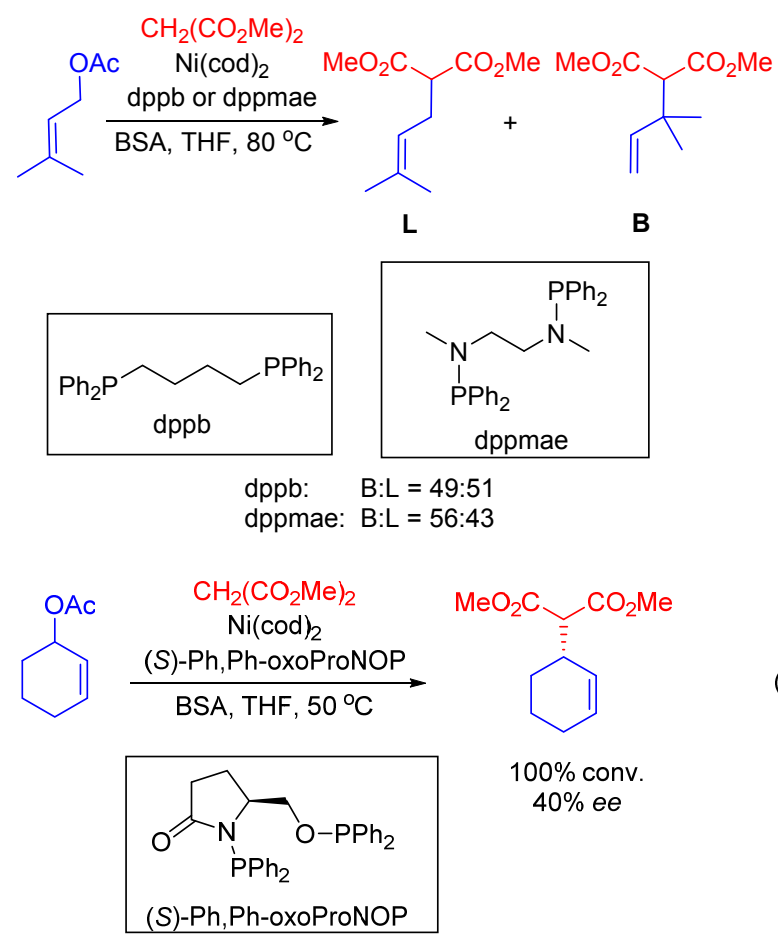

Walsh 小组 ${ }^{[32]}$ 首次采用二芳基甲烷作为亲核试剂, 与 Boc 保护的烯丙醇反应, 成功实现了二芳基甲烷的烯 丙基取代反应，亲核试剂芳基或杂芳基取代甲烷都适用 于该反应体系. 如 $\beta, \beta^{\prime}$-二吡啶甲烷与 $c i s$ 为主的外消旋 5-苯基-2-环己烯基叔丁氧羰基酯反应, 发生取代的碳原 子构型保持, 得到 cis 为主的外消旋产物(Eq. 18). 这说 明反应是软亲核试剂的进攻路径, 即亲核试剂进攻 $\pi$-烯 丙基中间体而不是进攻金属中心. 他们对 178 种手性膦 配体进行了考察, 最终篮选出最优配体 L6, 反应可以取 得高达 $92 \% e e$ 的对映选择性(Eq. 19). 对于镍催化的烯 丙基取代反应来说, 实现这样优秀的不对称控制是十分 难得的.
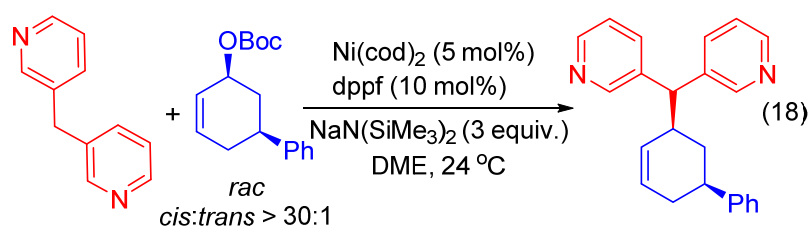

rac, $89 \%$ yield cis:trans $=15: 1$

烯丙基取代反应常用的烯丙基前体一般带有良好 的离去基团, 如醋酸酯、碳酸酯和卤代物等. 相比这些 活化的底物, 如果直接以烯丙醇为烯丙基前体, 则生成 的副产物为水. 但是, 烯丙醇的反应活性较低, 通常需 使用外部活化试剂如砷氧化物 ${ }^{[3]}$ 、嗍烷衍生物 ${ }^{[34]}$ 和钛添
加剂 ${ }^{[35]}$ 活化烯丙醇.

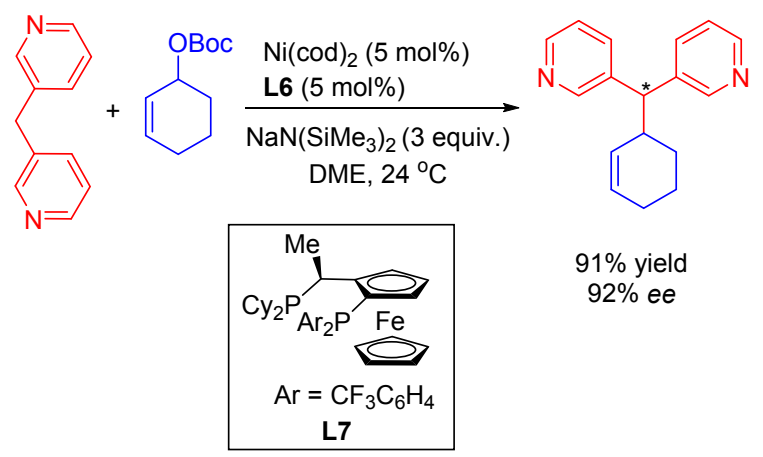

Mashima 小组 ${ }^{[36]}$ 在 2016 年报道了 $\mathrm{Ni}(\operatorname{cod})_{2} /(S)-(-)-$ $2,2^{\prime}$-双 (二苯基膦)- $5,5^{\prime}, 6,6^{\prime}, 7,7^{\prime}, 8,8^{\prime}$-八氢-1, $1^{\prime}$-联菘 $[(S)$ $\mathrm{H}_{8}$-BINAP]催化的烯丙醇与 $\beta$-酮酸酯的不对称烯丙基烷 基化反应. 该反应不需要添加剂来活化烯丙醇，反应能 够以优秀的对映选择性生成季碳手性中心，而且以直链 的产物为主(Eq. 20). 他们提出了可能的反应机理, 零价 镍双膦配合物与烯丙醇的烯烃配位生成配合物 $\mathbf{2 6}$, 接 着氧化加成生成羟基配位的烯丙基二价镍络合物 27 , 羟基随后㩲取 $\beta$-酮酸酯的 $\alpha$-H 生成 $\pi$-烯丙基镍中间体 28,28 经还原消除生成 29 , 最后, 烯丙醇与 29 发生配体 交换生成取代产物 $\mathbf{3 0}$ 并再生 $\mathbf{2 6}$, 完成催化循环(Scheme 8).

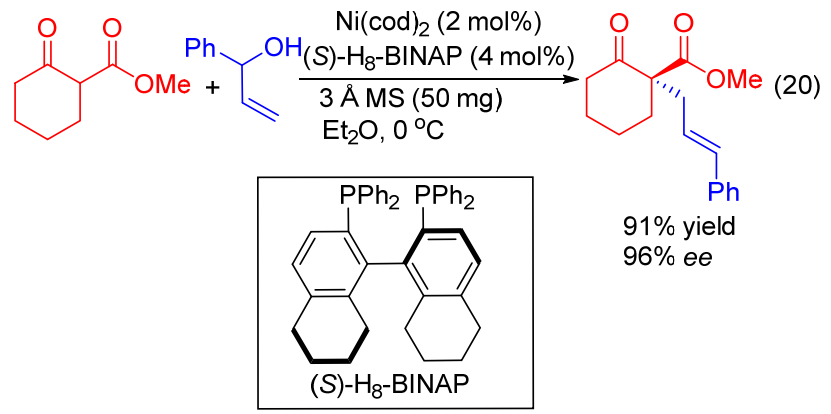

同年, Sauthier 和 Bonin 小组 ${ }^{[37]}$ 报道了 $\mathrm{Ni}(\operatorname{cod})_{2} / \mathrm{dppb}$ 催化的烯丙醇与软亲核试剂的双烯丙基化反应. 一些软 亲核试剂如 $\beta$-酥酯、 $\beta$-二酮和丙二酸酯都可应用于该反 应体系(Eq. 21). 此外, Sauthier 小组 ${ }^{[38]}$ 还报道了镍催化 酫的 $\alpha$-烯丙基化反应. 在以往钯催化醛的 $\alpha$-烯丙基化反 应中, 大多数例子都需要使用如硼烷衍生物 ${ }^{[39]}$ 、布朗斯 特酸 ${ }^{[40]}$ 和胺(形成烯胺) ${ }^{[41]}$ 等活化试剂. 该反应不需要活 化试剂, 使用 $1 \mathrm{~mol} \% \mathrm{Ni}(\mathrm{cod})_{2}, 2 \mathrm{~mol} \% \mathrm{dppf}$ 作催化剂, 在 $80{ }^{\circ} \mathrm{C}$ 的甲醇溶液中, $\alpha$-取代的醛或 $\alpha, \beta$-不饱和醛与烯 丙醇的反应可以顺利进行, 水是唯一副产物(Eq. 22).

最近, 杨东旭和王锐 ${ }^{[42]}$ 发展了以手性二胺作配体 的不对称烯丙基烷基化反应. 咪唑酮与硝基取代的烯丙 基醋酸酯反应，得到一系列手性 $\alpha$-烯丙基取代的酮类化 


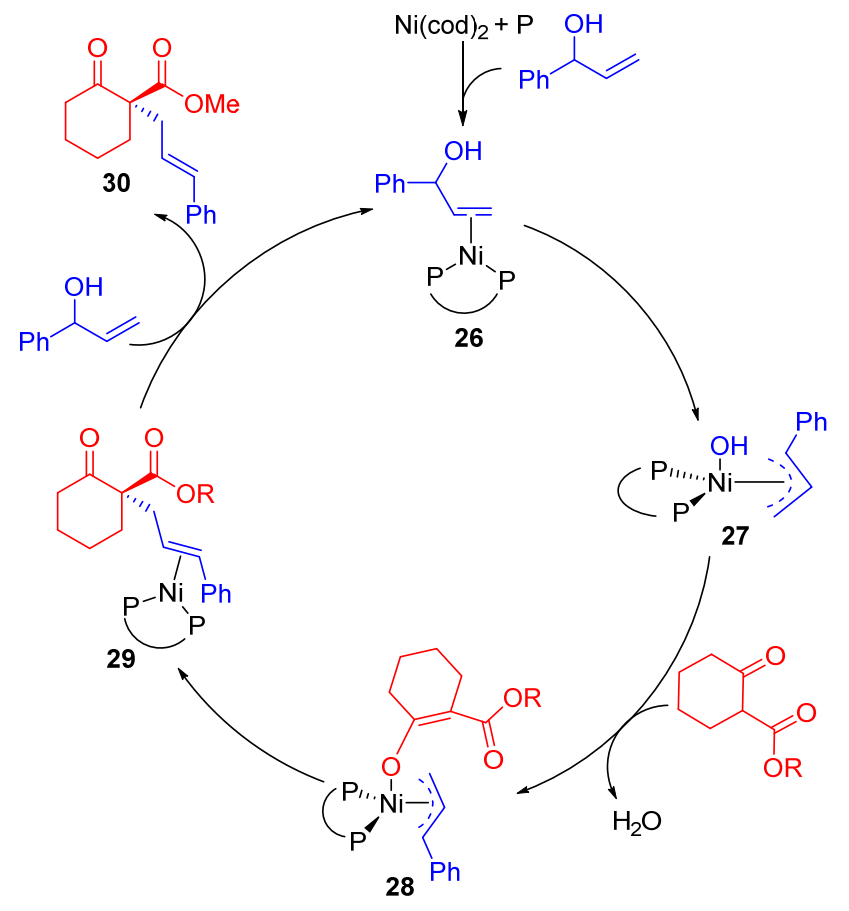

图式 8 镍催化 $\beta$-酮酸酯与烯丙醇可能的反应机理

Scheme 8 Plausible reaction mechanism of nickel-catalyzed reaction of $\beta$-ketoesters with allylic alcohols
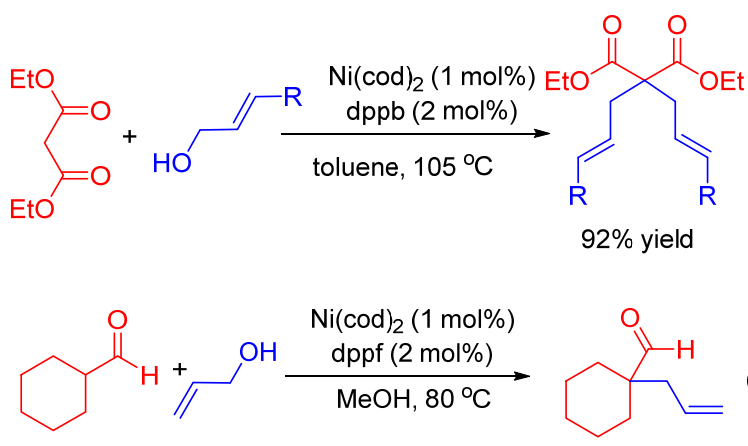

$96 \%$ yield

合物，给出中等到良好的收率及优秀的对映选择性(Eq. 23). 2018 年, Stoltz 小组 ${ }^{[43]}$ 首次报道了镍催化的 $\alpha$-酰基 内酯或内酰胺的不对称烯丙基取代反应. $\alpha$-酰基内酯和 内酰胺可以用作构建季碳手性中心的亲核试剂, $\alpha$-酰基 取代基也为产物的进一步转化提供了可能. 此外, 内酯 的开环反应还可以转化非环状含季碳手性中心化合物. 内酰胺的消除反应可以实现哌啶环的直接官能团化, 而 哌啶环又是含氮药物分子中最常见的杂环. 因此发展内 酯和内酰胺的烯丙基取代反应极具合成价值. Stoltz 小 组利用商业可得的手性双膦配体 $(R)-2,2^{\prime}, 6,6^{\prime}$-四甲氧 基-4,4'-双 (二苯基膦)-3,3'-联吡啶 $[(R)-\mathrm{P}$-phos $]$ 实现了烯 丙醇与 $\alpha$-酰基内酯和内酰胺的不对称烯丙基取代反应, 以最高达 $90 \% e e$ 的对映选择性生成季碳手性中心产物 (Eq. 24), 该类产物可转化为多官能团化的手性砌块.
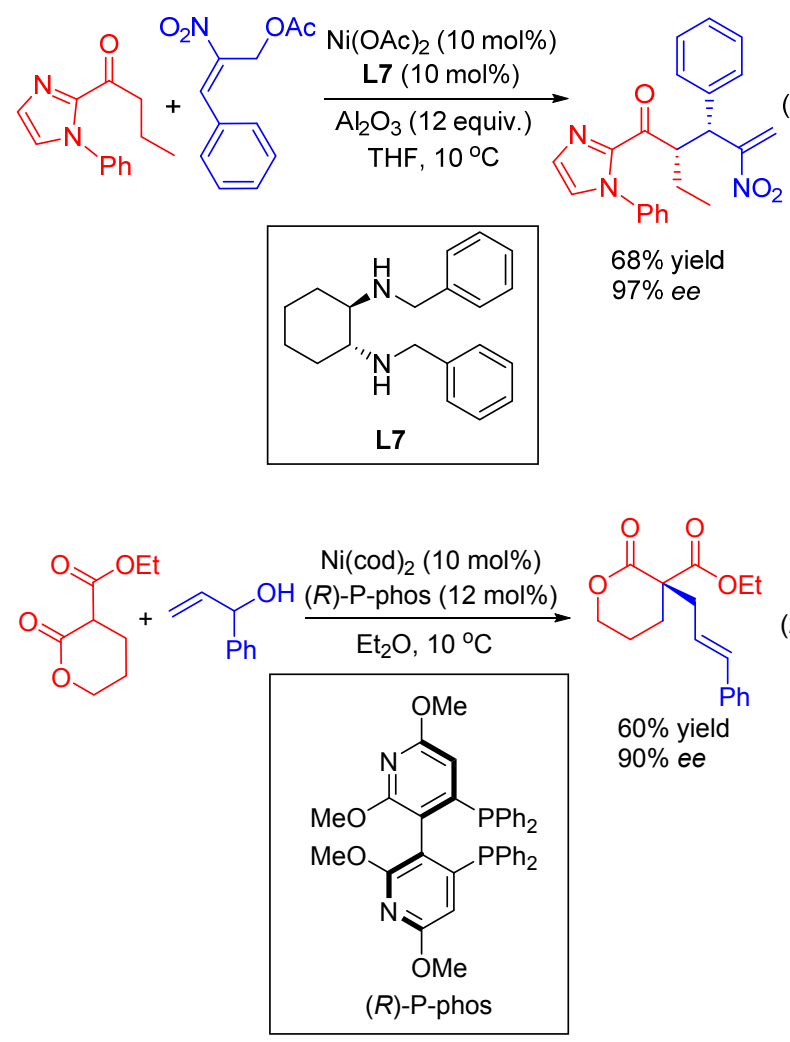

\section{5 其他亲核试剂}

1995 年, Ikeda 小组 ${ }^{[4]}$ 研究了烯丙基卤化物与炔基 锡试剂的烯丙基取代反应. 在 THF 回流下, Ni(acac $)_{2} /$ $\mathrm{PPh}_{3}$ 催化得到 1,4-烯炔产物, 其他膦配体, 如 $\mathrm{P}(\mathrm{OEt})_{3}$ 、 $\mathrm{P}(\mathrm{OPh})_{3}$ 也能催化该反应(Eq. 25).

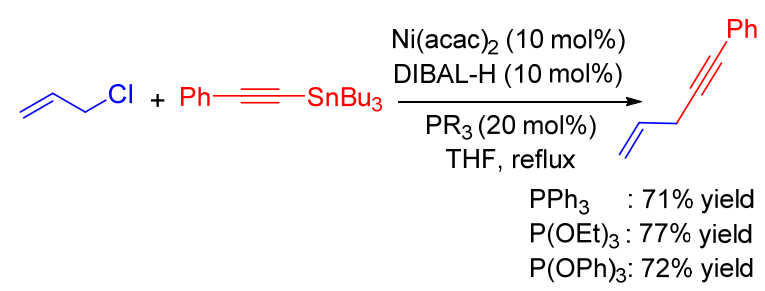

在镍催化的反应中，烯烃用作亲核试剂早有报 道 ${ }^{[45]}$, 但使用简单烯烃如乙烯、丙烯的烯丙基取代反应 在最近几年才被报道. 2010 年, Jamison 小组 ${ }^{[46]}$ 报道了首 例简单烯烃参与的烯丙基取代反应. 在三乙基硅基三氟 甲磺酸酯(TESOTf)和三乙胺存在下, 由 $\mathrm{Ni}(\operatorname{cod})_{2} /$ 三(邻 甲氧基苯基 $)$ 膦 $\left[\mathrm{P}(o \text {-anisyl })_{3}\right]$ 催化肉桂醇衍生物与简单烯 烃反应，可得到以 1,4-二烯为主的产物(Eq. 26). 这种方 法适用范围广，乙烯与各种肉桂醇衍生物反应良好，包 括带有易离去基团的肉桂醇衍生物，例如醋酸酯、烯丙 基氯和碳酸酯; 带有不易离去基团的肉桂醇衍生物，例 如烷基醚、三甲基硅醚，甚至肉桂醇也能顺利反应。这 是使用简单烯烃参与的烯丙基取代反应的重要进展. 


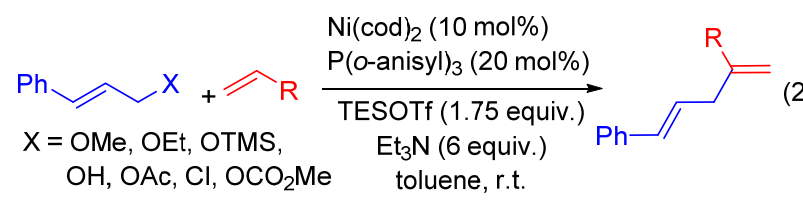

2011 年, Jamison 小组 ${ }^{[4]}$ 发展了烯烃和芐氯的分子 间苦基化反应. 以往的烯烃组分大多是带有官能团的取 代烯烃, 如丙烯酸酯、苯乙烯和 $N$-乙烯基酰胺, 而脂肪 族烯烃用于茮基化尚未实现. 而且, 通常在 $100 \sim$ $130{ }^{\circ} \mathrm{C}$ 下进行, 产物容易发生烯烃异构化. 1,1-二取代 烯烃在许多生物活性分子中普遍存在, 还是非常有用的 中间体 ${ }^{[48]}$, 但与 1,2 -二取代烯烃合成相比, 使用简单烯 烃直接构建 1,1-二取代烯烃的方法要少的多 ${ }^{[49]}$. Jamison 小组发展了镍催化简单烯烃与茮氯的反应, 各种取代的 脂肪族烯烃在该体系下都能够顺利发生反应, 反应在室 温下进行, 生成 1,1-二取代的烯烃衍生物(Eq. 27). 他们 分离得到了 $\mathrm{Ni}\left(\eta^{3}-\mathrm{CH}_{2} \mathrm{C}_{6} \mathrm{H}_{5}\right)\left(\mathrm{PCy}_{2} \mathrm{Ph}\right) \mathrm{Cl}$ 中间体 33, 其结 构通过单晶 $\mathrm{X}$ 射线衍射得以验证，并对其反应的机理进 行了假设(Scheme 9). 络合物 32 与苄氯氧化加成生成 $\eta^{3}-\mathrm{CH}_{2} \mathrm{C}_{6} \mathrm{H}_{5}$ 镍中间体 33 , 在三乙基硅基三氟甲磺酸酯 作用下, 氯被置换为三氟甲磺酸根, 生成中间体 $\mathbf{3 4}$, 烯 烃插入生成中间体 35, 35 发生 $\beta$ - $\mathrm{H}$ 消除, 得到 1,1 -二取 代的产物 36 和络合物 $\mathbf{3 7 , 3 7}$ 在三乙胺存在下再生 $\mathbf{3 2}$.

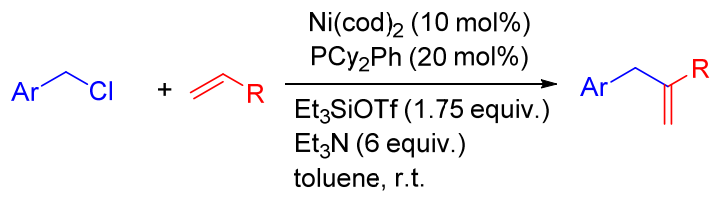

在前面的工作中, 多使用 $\mathrm{Ni}(\operatorname{cod})_{2}$ 作为零价镍来源, 虽然已经有很好的实验室合成方法, 但它需要 Schlenk 管或手套箱操作, 需要在惰性气氛下储存和使用. Jamison 小组 ${ }^{[50]}$ 希望通过设计空气稳定的催化剂, 摆脱 对惰性气氛技术的依赖, 使得反应在操作上更加方便简 单. 于是他们合成了新型催化剂 $\mathbf{C 4}$, 以环己基氯为起 始原料, 三步反应即可得到(Scheme 10). 这种催化剂不 仅合成简单, 催化活性高, 并且能够在空气中稳定存在. 他们将这种催化剂用于烯烃和茮基氯化物的取代反应, 不仅不需要惰性气氛操作, 而且以高收率和多数大于 95：5 的区域选择性生成烯丙基苯衍生物(Eq. 28).

\section{2 碳-杂原子键的构建}

\section{1 胺作为亲核试剂}

早在 1973 年, Furukawa 等 ${ }^{[51]}$ 研究了镍催化烯丙醇 或烯丙基醚与吗啉的反应，反应可以顺利生成相应的烯 丙基胺(Eq. 29). 后来, Moberg 小组 ${ }^{[52]}$ 和 Yamamoto 小 组 ${ }^{[53]}$ 分别对该反应的机理进行了研究, 认为镍与烯丙

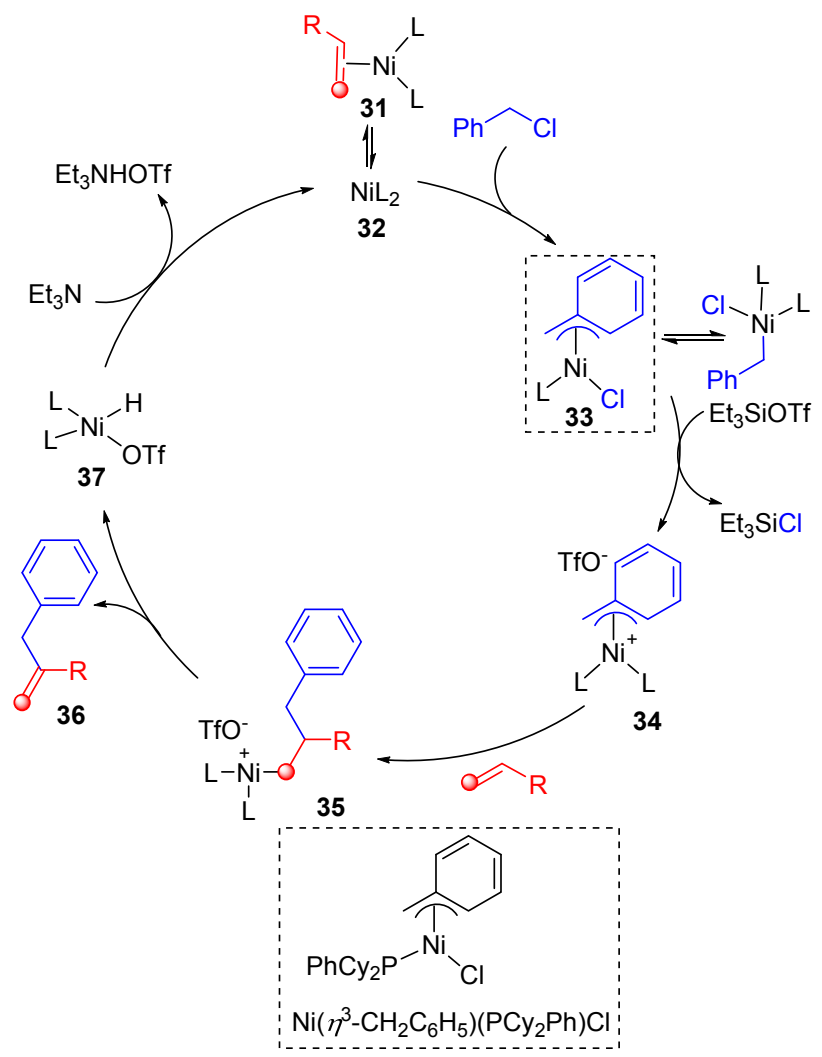

图式 9 镍催化苠基氯化物和简单烯烃可能的反应机理

Scheme 9 Possible mechanism of nickel-catalyzed reactions of benzyl chlorides with simple olefins

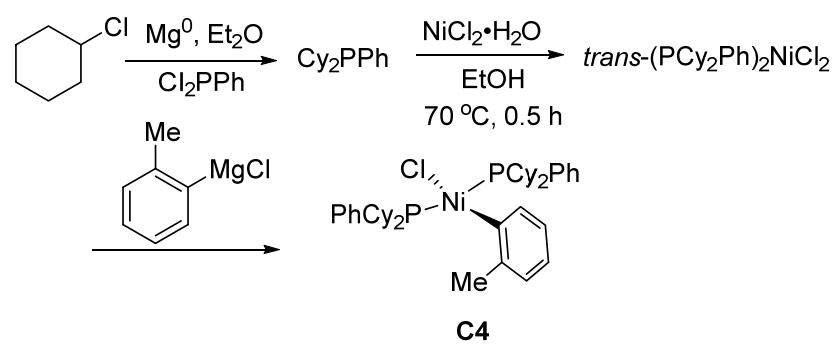

图式 10 合成催化剂 trans- $\left(\mathrm{PCy}{ }_{2} \mathrm{Ph}\right)_{2} \mathrm{Ni}(o$-tolyl $) \mathrm{Cl}$ Scheme 10 Synthesis of trans- $\left(\mathrm{PCy}{ }_{2} \mathrm{Ph}\right)_{2} \mathrm{Ni}(o$-tolyl $) \mathrm{Cl}$

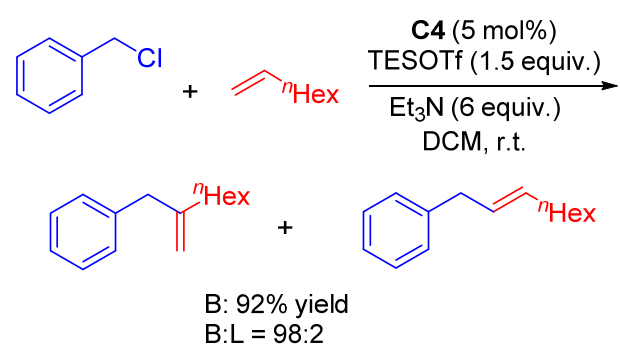

醇氧化加成生成 $\pi$-烯丙基中间体，然后接受亲核试剂进 攻. 1998 年, Mortreux 小组 ${ }^{[54]}$ 设计了二乙胺与烯丙基化 合物的取代反应(Eq. 30)，考察了底物、溶剂和盐等反应 参数对反应选择性及动力学的影响. 他们提出了可能的 
反应机理. 催化剂与烯丙基梄配位形成中间体 $\mathbf{3 8}$, 并发 生氧化加成形成中间体 39, 离去基团作为中间体 $\mathbf{4 0}$ 的 抗衡阴离子, 接下来二级胺进攻 $\mathbf{4 0}$, 配体解离生成相应 的产物 42, 同时再生催化物种, 完成催化循环(Scheme 11).

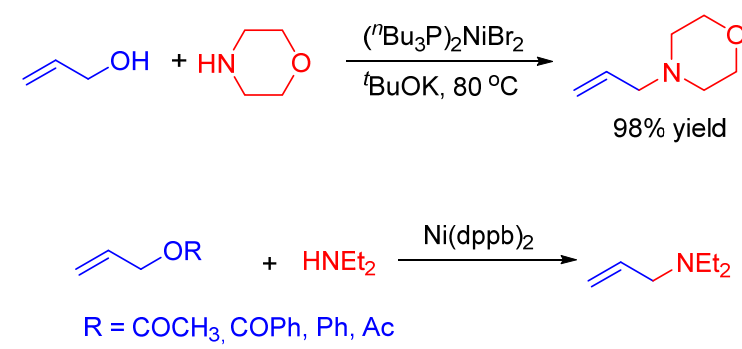

$\mathrm{R}=\mathrm{COCH}_{3} \mathrm{COPh}, \mathrm{Ph}, \mathrm{Ac}$

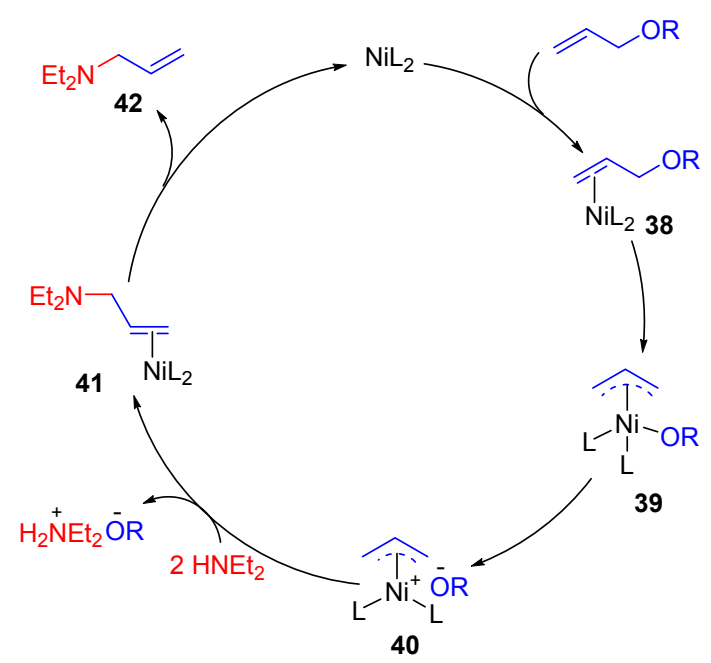

图式 11 镍催化二乙胺与烯丙基衍生物可能的反应机理

Scheme 11 Plausible reaction mechanism of nickel-catalyzed reaction of allylic derivatives with diethylamines

镍催化的不对称烯丙基胺化反应近年来才有报道. 2004 年, Berkowitz 小组 ${ }^{[55]}$ 在分子内烯丙基胺化反应中 应用原位酶篮选(ISES)来评估催化剂, 相对的 ISES 速率 能反映产物形成的相对速率. 在指定条件下, PMP 为 N保护基, $\mathrm{Ni}(\operatorname{cod})_{2}$ 为催化剂前体, 测试了一系列中心手 性、轴手性和平面手性的双齿配体. 当使用轴手性配体 $(R)-2,2^{\prime}$-双 (二苯基膦)-6, $6^{\prime}$-二甲氧-1, $1^{\prime}$-联苯 $[(R)-\mathrm{MeO}$ BIPHEP]时，可以取得 $88 \%$ 收率和 $75 \%$ ee 对映选择性 (Scheme 12). 这是首例零价镍催化的不对称烯丙基胺 化反应. 围绕这种新颖的不对称胺化反应，作者合成了 $L$-乙烯基甘氨酸衍生物.

2015 年, Carpentier, Ogoshi 和 Mashima 等 ${ }^{[56]}$ 发展了 $\mathrm{Ni}(\operatorname{cod})_{2} / \mathrm{dppf}$ 催化的烯丙醇直接胺化反应. $\mathrm{Ni}(\operatorname{cod})_{2}$ 用量 可以降低至 $0.5 \mathrm{~mol} \%$ ，配体 dppf 仅使用 $1 \mathrm{~mol} \%$. 通过 添加 ${ }^{n} \mathrm{Bu}_{4} \mathrm{NOAc}$ 和 $3 \AA$ 分子篮, 以高产率获得相应的烯 丙基胺. 值得注意的是, ${ }^{n} \mathrm{Bu}_{4} \mathrm{NOAc}$ 作用显著. 在相同条 件下，不使用 ${ }^{n} \mathrm{Bu}_{4} \mathrm{NOAc}$ ，产物收率为 $33 \%$ ，加入 2.5
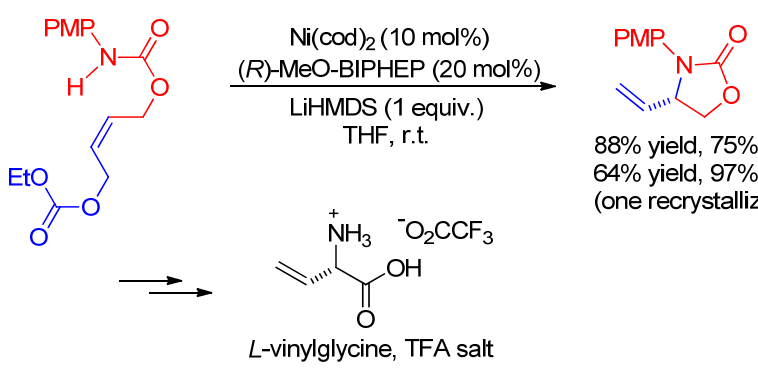

$88 \%$ yield, $75 \%$ ee $64 \%$ yield, $97 \%$ ee (one recrystallization)

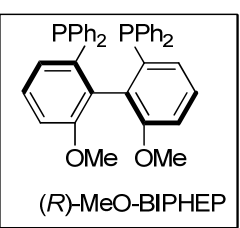

图式 12 镍催化分子内不对称烯丙基胺化反应

Scheme 12 Nickel-catalyzed intramolecular asymmetric allylic amination reaction

$\mathrm{mol} \%{ }^{n} \mathrm{Bu}_{4} \mathrm{NOAc}$ 产物收率可提高至 $82 \%$ (表 2). 为了阐 明 ${ }^{n} \mathrm{Bu}_{4} \mathrm{NOAc}$ 所起的作用，作者分离和表征了一些重要 中间体，与先前在钯和铂催化中广泛认同的阳离子四配 位络合物不同，在该反应体系下醋酸根离子与 $\eta^{3}$-烯丙 基镍配位, 形成电中性的五配位的络合物 $\left(\eta^{3}\right.$-allyl) Ni(dppf)OAc 43, 有助于亲核进攻 ${ }^{[57]}$.

表 2 四丁基醋酸铵对反应收率的影响

Table 2 Effect of ${ }^{n} \mathrm{Bu}_{4} \mathrm{NOAc}$ on reaction yield

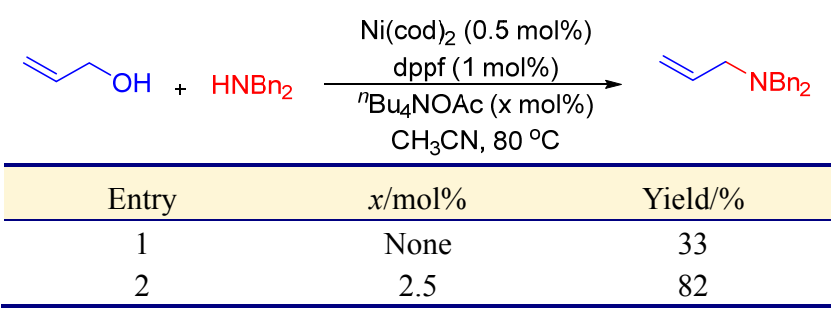

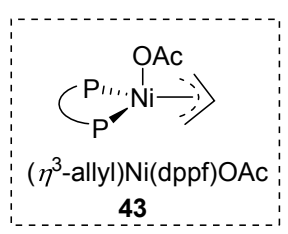

2015 年, Sauthier 小组 ${ }^{[58]}$ 报道了二[1,2-双 (二苯基膦 甲基苯]镍 $\left[\mathrm{Ni}(\mathrm{dppmb})_{2}\right]$ 催化酰胺的 $\mathrm{N}$-烯丙基化反应. 反 应在中性条件下进行, 不需要添加剂来活化烯丙醇, 但 由于使用过量的烯丙醇生成双烯丙基取代的副产物(Eq. 31). 同时，烯丙醇会发生自身醚化的竞争反应，形成二 烯丙基醚.

\section{2 含硫化合物作为亲核试剂}

使用硫亲核试剂的镍催化烯丙基取代反应最早是 在 1983 年由 Julia 和 Cuvigny ${ }^{[59]}$ 报道. 对甲苯亚磺酸钠 与烯丙基醋酸酯反应, 分别以 $\mathrm{NiBr}_{2} / \mathrm{PhP}\left(\mathrm{O}^{i} \mathrm{Pr}\right)_{2}$ 和 


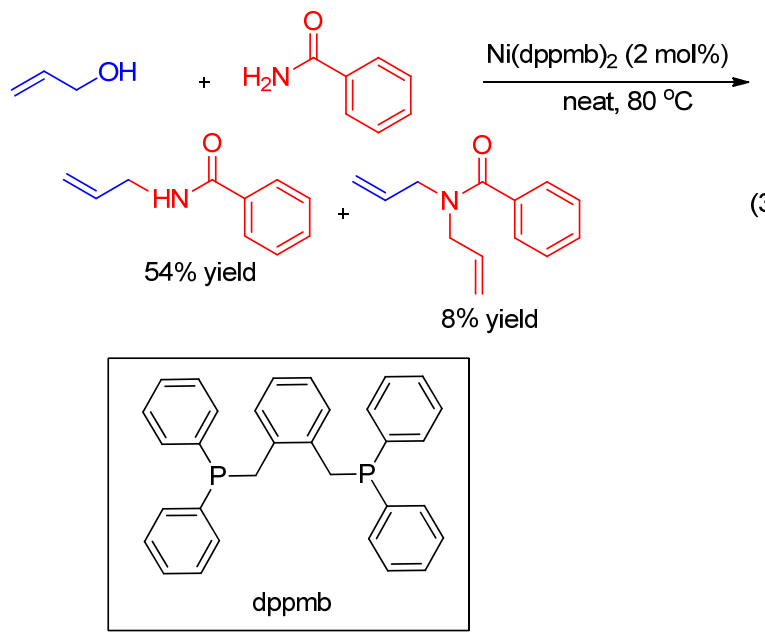

$\mathrm{Ni}\left(\mathrm{PPh}_{3}\right)_{2} \mathrm{Cl}_{2}$ 作为催化剂, 可以选择性地生成直链或支 链烯丙基砜产物(Scheme 13).

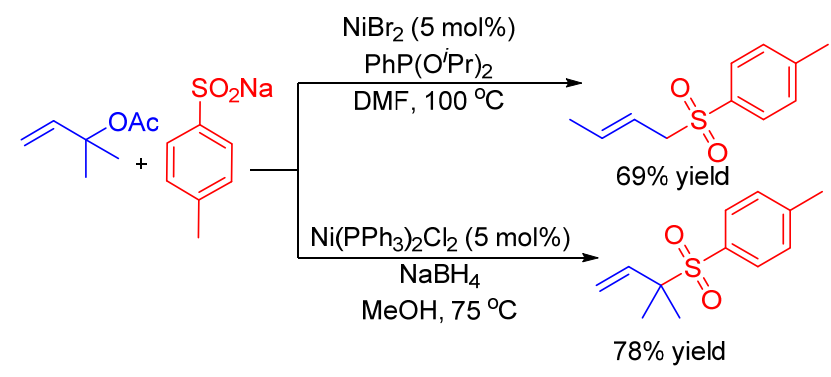

图式 13 镍催化烯丙基醋酸酯与对甲苯亚磺酸钠的取代反应 Scheme 13 Nickel-catalyzed substitution of allylic acetates with $p$-tolSO $\mathrm{S}_{2} \mathrm{Na}$

2007 年, Takeda 小组 ${ }^{[60]}$ 利用空气稳定的 Ni[P$\left.(\mathrm{OEt})_{3}\right]_{4}$ 催化剂, 实现了烯丙基醋酸酯与硫醇的烯丙基 硫醚化反应, 得到构型保持的烯丙基硫化物. 如使用 $Z$ 式烯丙基醋酸酯则得到 $Z$ 式取代的产物(Eq. 32), 反之 使用 $E$ 式烯丙基醋酸酯则得到 $E$ 式取代的产物(Eq. 33). 烯丙基醋酸酯与醇或酚同样能够顺利发生反应，也得到 区域专一性和立体专一性的产物(Eq. 34).

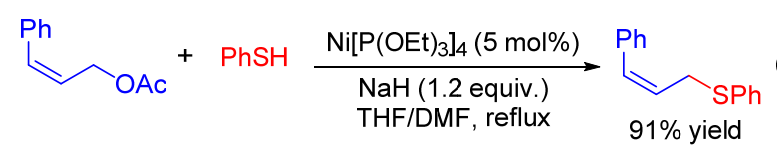

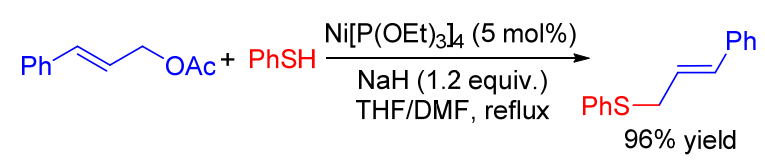

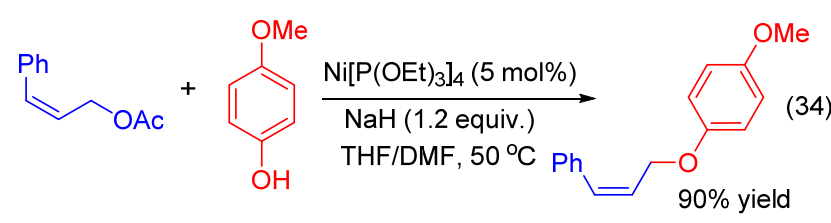

\section{3 总结与展望}

在过去 50 年里, 镍催化的烯丙基取代反应研究取 得了不错的进展. 有机化学家们使用格氏试剂作亲核试 剂的的早期研究, 奠定了镍催化烯丙基取代反应的研究 基础. 随后陆续实现了有机硼、有机锌试剂等硬亲核试 剂, $\beta$-二酮酯、二芳基甲烷等软亲核试剂以及二级胺等 杂原子亲核试剂参与的烯丙基取代反应.一些高选择性 (区域、立体和对映选择性)烯丙基取代反应也得以实现. 这些研究成果为构建碳一碳键、碳一杂原子键提供了强有 力的方法, 同时这些方法在天然产物及药物活性分子中 间体的合成中发挥了举足轻重的作用.

尽管如此，镍催化的烯丙基取代反应仍存在一些亟 待解决的问题, 发展更加高效高选择性的催化反应依然 是研究重点, 主要包括以下几个方面: (1)进一步阐明反 应的机理以及探索反应选择性控制的规律, 为设计新反 应和新配体提供理论依据; (2)发展高对映选择性的催化 新反应; (3)发展高效的新催化体系(包括新配体和镍源) 以提高催化效率; (4)进一步拓展镍催化烯丙基取代反应 在有机合成中的应用.

不难看出，镍催化的烯丙基取代反应已表现出独特 的发展潜力, 是一个有待开发的广阔领域, 也已经取得 了一些研究成果. 我们预计未来会有大量关于此类反应 的报道, 这些报道将进一步证明这一方法的重要性, 并 推动该领域的发展.

\section{References}

[1] For selected reviews, see: (a) Helmchen, G. J. Organomet. Chem. 1999, 576, 203.

(b) Tenaglia, A.; Heumann, A. Angew. Chem., Int. Ed. 1999, 38, 2180 .

(c) Trost, B. M. Chem. Pharm. Bull. 2002, 50, 1.

(d) Kazmaier, U. Curr. Org. Chem. 2003, 7, 317.

(e) Trost, B. M. J. Org. Chem. 2004, 69, 5813.

(f) Jensen, T.; Fristrup, P. Chem.-Eur. J. 2009, 15, 9632.

(g) Milhau, L.; Guiry, P. J. Top. Organomet. Chem. 2012, 38, 95.

[2] For selected reviews, see: (a) Takeuchi, R.; Kezuka, S. Synthesis 2006, 3349 .

(b) Helmchen, G.; Dahnz, A.; Dübon, P.; Schelwies, M.; Weihofen, R. Chem. Commun. 2007, 675.

(c) Hartwig, J. F.; Stanley, L. M. Acc. Chem. Res. 2010, 43, 1461.

(d) Hartwig, J. F.; Pouy, M. J. Top. Organomet. Chem. 2011, 34, 169.

(e) Liu, W.-B.; Xia, J.-B.; You, S.-L. Top. Organomet. Chem. 2012, $38,155$.

(f) Tosatti, P.; Nelson, A.; Marsden, S. P. Org. Biomol. Chem. 2012, $10,3147$.

(g) Helmchen, G. In Molecular Catalysis, Eds.: Gade, L. H.; Hofmann, P., Wiley-VCH, Weinheim, 2014, pp. 235 254.

(h) Zhuo, C.-X.; Zheng, C.; You, S.-L. Acc. Chem. Res. 2014, 47, 2558.

(i) Hethcox, J. C.; Shockley, S. E.; Stoltz, B. M. ACS Catal. 2016, $6,6207$.

(j) Qu, J.; Helmchen, G. Acc. Chem. Res. 2017, 50, 2539.

[3] For selected reviews, see: (a) Evans, P. A.; Nelson, J. D. J. Am. Chem. Soc. 1998, 120, 5581. 
(b) Selvakumar, K.; Valentini, M.; Pregosin, P. S.; Albinati, A. Organometallics 1999, 18, 4591 .

(c) Hayashi, T.; Okada, A.; Suzuka, T.; Kawatsura, M. Org. Lett. 2003, 5, 1713 .

(d) Ashfeld, B. L.; Miller, K. A.; Martin, S. F. Org. Lett. 2004, 6, 1321

[4] For selected reviews, see: (a) Minami, I.; Shimizu, I.; Tsuji, J. J. Organomet. Chem. 1985, 296, 269.

(b) Zhang, S.-W.; Mitsudo, T.; Kondo, T.; Watanabe, Y. J. Organomet. Chem. 1993, 450, 197.

(c) Matsushima, Y.; Onitsuka, K.; Kondo, T.; Mitsudo, T.; Takahashi, S. J. Am. Chem. Soc. 2001, 123, 10405.

(d) Trost, B. M.; Fraisse, P. L.; Ball, Z. T. Angew. Chem., Int. Ed. 2002, 41, 1059 .

(e) Mbaye, M. D.; Demerseman, B.; Renaud, J.-L.; Toupet, L.; Bruneau, C. Angew. Chem., Int. Ed. 2003, 42, 5066.

(f) Hermatschweiler, R.; Fernandez, I.; Breher, F.; Pregosin, P. S.; Veiros, L. F.; Calhorda, M. J. Angew. Chem., Int. Ed. 2005, 44, 4397.

(g) Kawatsura, M.; Ata, F.; Wada, S.; Hayase, S.; Uno, H.; Itoh, T. Chem. Commun. 2007, 298.

[5] For selected reviews, see: (a) Consiglio, G.; Waymouth, R. M. Chem. Rev. 1989, 89, 257.

(b) Ho, C.-Y.; Schleicher, K. D.; Chan, C.-W.; Jamison, T. F. Synlett 2009, 2565.

(c) Pigge, F. C. Synthesis 2010, 1745.

[6] Henrion, M.; Ritleng, V.; Chetcuti, M. J. ACS Catal. 2015, 5, 1283.

[7] For selected examples, see:

(a) Schaub, T.; Backes, M.; Radius, U. J. Am. Chem. Soc. 2006, $128,15964$.

(b) Rosen, B. M.; Quasdorf, K. W.; Wilson, D. A.; Zhang, N.; Resmerita, A.-M.; Garg, N. K.; Percec, V. Chem. Rev. 2011, 111, 1346

(c) Li, B.-J.; Yu, D.-G.; Sun, C.-L.; Shi, Z.-J. Chem.-Eur. J. 2011, 17, 1728 .

(d) Tobisu, M.; Xu, T.; Shimasaki, T.; Chatani, N. J. Am. Chem. Soc. 2011, 133, 19505.

[8] Chuit, C.; Felkin, H.; Frajerman, C.; Roussi, G.; Swierczewski, G. Chem. Commun. 1968, 1604.

[9] Felkin, H.; Swierczewski, G. Tetrahedron Lett. 1972, 15, 1433

[10] Felkin, H.; Joly-Goudket, M.; Davies, S. G. Tetrahedron Lett. 1981, 22, 1157.

[11] Consiglio, G.; Morandini, F.; Piccolol, O. Helv. Chim. Acta 1980, 63, 987.

[12] Consiglio, G.; Morandini, F.; Piccolo, O. J. Chem. Soc., Chem. Commun. 1983, 112.

[13] Consiglio, G.; Piccolo, O.; Roncetti, L.; Morandini, F. Tetrahedron 1986, 42, 2043

[14] Hiyama, T.; Wakasa, N. Tetrahedron Lett. 1985, 26, 3259.

[15] Nomura, N.; RajanBabu, T. V. Tetrahedron Lett. 1997, 38, 1713.

[16] Gomez-Bengoa, E.; Heron, N. M.; Didiuk, M. T.; Luchaco, C. A.; Hoveyda, A. H. J. Am. Chem. Soc. 1998, 120, 7649.

[17] Chung, K.-G.; Miyake, Y.; Uemura, S. J. Chem. Soc., Perkin Trans. $12000,2725$.

[18] Trost, B. M.; Spagnol, M. D. J. Chem. Soc., Perkin Trans. 1 1995, 2083.

[19] (a) Kobayashi, Y.; Ikeda, E. J. Chem. Soc., Chem. Commun. 1994, 1789 .

(b) Kobayashi, Y.; Tokoro, Y.; Watatani, K. Eur. J. Org. Chem. 2000, 3825 .

(c) Kobayashi, Y.; Watatani, K.; Kikori, Y.; Mizojiri, R. Tetrahedron Lett. 1996, 37, 6125

(d) Kobayashi, Y.; Takahisa, E.; Usmani, S. B. Tetrahedron Lett. 1998, 39, 597

(e) Kobayashi, Y.; Takahisa, E.; Usmani, S. B. Tetrahedron Lett. 1998, 39, 601

(f) Jimenez-Aquino, A.; Flegeau, E. F.; Schneider, U.; Kobayashi, S. Chem. Commun. 2011, 47, 9456.
[20] Chung, K.-G.; Miyake, Y.; Uemura, S. J. Chem. Soc., Perkin Trans. $12000,15$.

[21] Chen, H.; Deng, M.-Z. J. Organomet. Chem. 2000, 603, 189.

[22] (a) Shields, J. D.; Ahneman, D. T.; Graham, T. J. A.; Doyle, A. G. Org. Lett. 2014, 16, 142.

(b) Sylvester, K. T.; Wu, K.; Doyle, A. G. J. Am. Chem. Soc. 2012, 134, 16967.

(c) Graham, T. J. A.; Shields, J. D.; Doyle, A. G. Chem. Sci. 2011, 2, 980 .

[23] Srinivas, H. D.; Zhou, Q.; Watson, M. P. Org. Lett. 2014, 16, 3596.

[24] Nazari, S. H.; Bourdeau, J. E.; Talley, M. R.; Valdivia-Berroeta, G. A.; Smith, S. J.; Michaelis, D. J. ACS Catal. 2018, 8, 86.

[25] Chau, S. T.; Lutz, J. P.; Wu, K.; Doyle, A. G. Angew. Chem., Int. Ed. 2013, 52, 9153.

[26] For some recent examples synthesis of biologically active 4-piperidines, see: (a) Tawara, J. N.; Lorenz, P. F.; Stermitz, R. J. Nat. Prod. 1999, 62, 321.

(b) Watson, P. S.; Jiang, B.; Scott, B. Org. Lett. 2000, 2, 3679.

(c) Brooks, C. A.; Comins, D. L. Tetrahedron Lett. 2000, 41, 3551.

[27] (a) Wu, D.; Wang, Z.-X. Org. Biomol. Chem. 2014, 12, 6414.

(b) Wu, D.; Tao, J.-L.; Wang, Z.-X. Org. Chem. Front. 2015, 2, 265.

[28] Tao, J.-L.; Yang, B.; Wang, Z.-X. J. Org. Chem. 2015, 80, 12627.

[29] Yang, B.; Wang, Z.-X. J. Org. Chem. 2017, 82, 4542.

[30] Bricout, H.; Carpentier, J.-F.; Mortreux, A. J. Chem. Soc., Chem. Commun. 1995, 1863.

[31] Bricout, H.; Carpentier, J.-F.; Mortreux, A. Tetrahedron Lett. 1996, $37,6105$.

[32] Sha, S.-C.; Jiang, H.; Mao, J.; Bellomo, A.; Jeong, S. A.; Walsh, P. J. Angew. Chem., Int. Ed. 2016, 55, 1070.

[33] For selected examples, see:

(a) Lu, X.; Lu, L. J. Organomet. Chem. 1986, 307, 285

(b) Lu, X.; Lu, L.; Sun, J. J. Mol. Catal. 1987, 41, 245.

(c) Lu, X.; Jiang, X.; Tao, X. J. Organomet. Chem. 1988, 344, 109.

[34] For selected examples, see:

(a) Starý, I.; Stará, I. G.; Kočovský, P. Tetrahedron Lett. 1993, 34, 179 .

(b) Starý, I.; Stará, I. G.; Kočovský, P. Tetrahedron 1994, 50, 529.

(c) Tamaru, Y.; Horino, Y.; Araki, M.; Tanaka, S.; Kimura, M. Tetrahedron Lett. 2000, 41, 5705.

(d) Takacs, J. M.; Jiang, X.-T.; Leonov, A. P. Tetrahedron Lett. 2003, 44, 7075 .

(e) Kimura, M.; Mukai, R.; Tanigawa, N.; Tanaka, S.; Tamaru, Y. Tetrahedron 2003, 59, 7767 .

[35] Itoh, K.; Hamaguchi, N.; Miura, M.; Nomura, M. J. Chem. Soc., Perkin Trans. 1 1992, 1, 2833.

[36] Kita, Y.; Kavthe, R. D.; Oda, H.; Mashima, K. Angew. Chem., Int. Ed. 2016, 55, 1098.

[37] Blieck, R.; Azizi, M. S.; Mifleur, A.; Roger, M.; Persyn, C.; Sauthier, M.; Bonin, H. Eur. J. Org. Chem. 2016, 1194.

[38] Bernhard, Y.; Thomson, B.; Ferey, V.; Sauthier, M. Angew. Chem., Int. Ed. 2017, 56, 7460.

[39] For selected examples, see:

(a) Kimura, M.; Horino, Y.; Mukai, R.; Tanaka, S.; Tamaru, Y. J. Am. Chem. Soc. 2001, 123, 10401.

(b) Kimura, M.; Shimizu, M.; Shibata, K.; Tazoe, M.; Tamaru, Y. Angew. Chem., Int. Ed. 2003, 42, 3392.

[40] Jiang, G.; List, B. Adv. Synth. Catal. 2011, 353, 1667.

[41] For selected examples, see:

(a) Ibrahem, I.; Clrdova, A. Angew. Chem., Int. Ed. 2006, 45, 1952.

(b) Mukherjee, S.; List, B. J. Am. Chem. Soc. 2007, 129, 11336.

(c) Jiang, G.; List, B. Angew. Chem., Int. Ed. 2011, 50, 9471.

[42] Wang, J.; Wang, P.; Wang, L.; Li, D.; Wang, K.; Wang, Y.; Zhu, H.; Yang, D.; Wang, R. Org. Lett. 2017, 19, 4826.

[43] Ngamnithiporn, A.; Jette, C. I.; Bachman, S.; Virgil, S. C.; Stoltz, B. M. Chem. Sci. 2018, 9, 2547.

[44] Cui, D.-M.; Hashimoto, N.; Ikeda, S.-I.; Sato, Y. J. Org. Chem. 1995, 60, 5752.

[45] For selected examples, see: (a) Ng, S.-S.; Ho, C.-Y.; Schleicher, K. 
D.; Jamison, T. F. Pure Appl. Chem. 2008, 80, 929.

(b) Ogoshi, S.; Haba, T.; Ohashi, M. J. Am. Chem. Soc. 2009, 131, 10350 .

[46] Matsubara, R.; Jamison, T. F. J. Am. Chem. Soc. 2010, 132, 6880.

[47] Matsubara, R.; Gutierrez, A. C.; Jamison, T. F. J. Am. Chem. Soc. 2011, 133, 19020.

[48] For selected examples, see: (a) Miller, J. A.; Negishi, E.-I. Tetrahedron Lett. 1984, 25, 5863.

(b) Sabarre, A.; Love, J. Org. Lett. 2008, 10, 3941.

[49] For selected examples, see:

(a) Milstein, D.; Stille, J. K. J. Am. Chem. Soc. 1979, 101, 4992.

(b) Kamlage, S.; Sefkow, M.; Peter, M. G. J. Org. Chem. 1999, 64, 2938.

(c) Zhang, S.; Marshall, D.; Liebeskind, L. S. J. Org. Chem. 1999, 64, 2796.

(d) Perez, I.; Sestelo, J. P.; Sarandeses, L. A. J. Am. Chem. Soc. 2001, 123, 4155.

[50] Standley, E. A.; Jamison, T. F. J. Am. Chem. Soc. 2013, 135, 1585.

[51] Furukawa, J.; Kui, J.; Yamamoto, K.; Tojo, T. Tetrahedron 1973, $29,3149$.

[52] Moberg, C. Tetrahedron Lett. 1980, 21, 4539.

[53] Yamamoto, T.; Ishizu, J.; Yamamoto, A. J. Am. Chem. Soc. 1981,
103,6863

[54] Bricout, H.; Carpentier, J.-F.; Mortreux, A. Tetrahedron 1998, 54, 1073.

[55] Berkowitz, D. B.; Maiti, G. Org. Lett. 2004, 6, 2661.

[56] Kita, Y.; Sakaguchi, H.; Hoshimoto, Y.; Nakauchi, D.; Nakahara, Y.; Carpentier, J.-F.; Ogoshi, S.; Mashima, K. Chem.-Eur. J. 2015, 21, 14571.

[57] For selected examples, see:

(a) Brunkan, N. M.; Jones, W. D. J. Organomet. Chem. 2003, 683, 77.

(b) Brunkan, N. M.; Brestensky, D. M.; Jones, W. D. J. Am. Chem. Soc. 2004, 126, 3627.

(c) Chaumonnot, A.; Lamy, F.; Sabo-Etienne, S.; Donnadieu, B.; Chaudret, B.; Barthelat, J.-C.; Galland, J.-C. Organometallics 2004, 23, 3363 .

(d) Acosta-Ramírez, A.; Muñoz-Hernández, M.; Jones, W. D.; Garcia, J. J. J. Organomet. Chem. 2006, 691, 3895.

[58] Azizi, M. S.; Edder, Y.; Karim, A.; Sauthier, M. Eur. J. Org. Chem. 2016, 3796.

[59] Cuvigny, T.; Julia, M. J. Organomet. Chem. 1983, 250, C21.

[60] Yatsumonji, Y.; Ishida, Y.; Tsubouchi, A.; Takeda, T. Org. Lett. 2007, 9, 4603 . 